OPEN ACCESS

Edited by:

Martin Witt

University Hospital Rostock, Germany

Reviewed by:

Veronica Alexandra Antipova,

Medical University of Graz, Austria

Andreas Wree,

University of Rostock, Germany

${ }^{*}$ Correspondence: Xiaoli Shen

shenxiaoli@qdu.edu.cn

Specialty section:

This article was submitted to

Neurodegeneration,

a section of the journal

Frontiers in Neuroscience

Received: 25 October 2020 Accepted: 11 January 2021

Published: 28 January 2021

Citation:

Chen H, LiX, Ma H, Zheng W and Shen X (2021) Reduction in Nesfatin-1 Levels in the Cerebrospinal Fluid and Increased Nigrostriatal Degeneration Following Ventricular Administration of Anti-nesfatin-1 Antibody in Mice.

Front. Neurosci. 15:621173 doi: 10.3389/fnins.2021.621173

\section{Reduction in Nesfatin-1 Levels in the Cerebrospinal Fluid and Increased Nigrostriatal Degeneration Following Ventricular Administration of Anti-nesfatin-1 Antibody in Mice}

\author{
Huanhuan Chen ${ }^{1}$, Xuelian Li' ${ }^{1}$, Hui Ma ${ }^{1}$, Wei Zheng ${ }^{2}$ and Xiaoli Shen ${ }^{1,2 *}$ \\ 'Department of Epidemiology and Health Statistics, Medical School of Qingdao University, Qingdao, China, ${ }^{2}$ School \\ of Health Sciences, Purdue University, West Lafayette, IN, United States
}

Nesfatin-1 is one of several brain-gut peptides that have a close relationship with the central dopaminergic system. Our previous studies have shown that nesfatin- 1 is capable of protecting nigral dopaminergic neurons against 1-methyl-4-phenyl-1,2,3,6tetrahydropyridine (MPTP)-induced neurotoxicity. A recent study also revealed a reduced blood level of nesfatin-1 in patients with Parkinson's disease (PD). The current study was designed to investigate whether reduced nesfatin-1 in cerebrospinal fluid (CSF) induces nigrostriatal system degeneration. An intra-cerebroventricular (ICV) injection technique was used to administer anti-nesfatin-1 antibody directly into the lateral ventricle of the brain. Enzyme-linked immunosorbent assay (ELISA) results showed that ICV injection of anti-nesfatin-1 antibody into the lateral ventricle of the brain once daily for 2 weeks caused a significant reduction in nesfatin-1 levels in the CSF (93.1\%). Treatment with anti-nesfatin-1 antibody resulted in a substantial loss (23\%) of $\mathrm{TH}$ positive $(\mathrm{TH}+$ ) dopaminergic neurons in the substantia nigra pars compacta (SNpc), as shown by immunofluorescence staining, a depletion in dopamine and its metabolites in the striatum detected by high-performance liquid chromatography (HPLC), and obvious nuclear shrinkage and mitochondrial lesions in dopaminergic neurons in the SNpc detected by transmission electron microscopy (TEM). Furthermore, the results from our Western blot and ELISA experiments demonstrated that anti-nesfatin-1 antibody injection induced an upregulation of caspase-3 activation, increased the expression of $p$-ERK, and elevated brain-derived neurotrophic factor (BDNF) levels in the SNpc. Taken together, these observations suggest that reduced nesfatin-1 in the brain may induce nigrostriatal dopaminergic system degeneration; this effect may be mediated via mitochondrial dysfunction-related apoptosis. Our data support a role of nesfatin-1 in maintaining the normal physiological function of the nigrostriatal dopaminergic system.

Keywords: nesfatin-1, nigrostriatal system, dopaminergic neuron, mitochondrion, Parkinson's disease, apoptosis, degeneration 


\section{INTRODUCTION}

Parkinson's disease (PD) is one of the most common neurodegenerative diseases in the world (Dawson and Dawson, 2003; de Lau and Breteler, 2006; Elbaz et al., 2016). Most PD patients display motor symptoms, including tremor, muscle rigidity, akinesia (or slow movement), and postural instability; patients also display non-motor symptoms, such as abnormal digestive tract function, mood disorders, and autonomic disturbances (Klockgether, 2004; Beitz, 2014). The clinical pathology includes the loss of dopaminergic neurons in the substantia nigra pars compacta ( $\mathrm{SNpc}$ ) with an ensuing significant reduction in dopamine levels in the striatum (Dauer and Przedborski, 2003; Sarkar et al., 2016; Balestrino and Schapira, 2020). Extensive data in the literature have linked the development of PD to genetic origins, environmental influences, oxidative stress, protein misfolding, and inflammation, among many other factors (Cacabelos, 2017; Delamarre and Meissner, 2017; Boulos et al., 2019). The etiology of PD, however, is not fully understood (Respondek et al., 2019; Bonam and Muller, 2020; Gilmozzi et al., 2020).

Recently, several brain-gut peptides, such as neurotensin, ghrelin, and glucagon-like peptide-1, were identified to play a significant role in regulating the function of the brain dopaminergic system (St-Gelais et al., 2006; Calsolaro and Edison, 2015; Yu et al., 2016). Nesfatin-1, an 82-amino acid polypeptide that is a product of the NEFA/NUCB2 gene identified in 2006, has been shown to have anorexigenic properties ( Oh et al., 2006; Stengel et al., 2010; Pałasz et al., 2012). In the brain, nesfatin-1 is expressed mostly in the paraventricular, arcuate, and supraoptic nuclei of the hypothalamus, the nucleus tractus solitarii, the dorsal nucleus of the vagus nerve, and the pituitary gland (Stengel and Taché, 2011; Li et al., 2014). Nesfatin-1 is relatively stable in the blood within 20 min after injection (Pan et al., 2007). Interestingly, this peptide can freely cross the blood-brain barrier in an unsaturated manner (Pan et al., 2007), allowing the delivery of nesfatin- 1 into the brain by peripheral injection for the treatment of brain diseases (Dong et al., 2019).

Early studies on nesfatin-1 were mainly focused on its inhibitory effects on eating, weight, and blood glucose regulation (Atsuchi et al., 2010; Su et al., 2010; Goebel et al., 2011; Stengel et al., 2011). Recent reports have also revealed the impacts of nesfatin-1 on reproduction, sleep, anxiety, epilepsy, and depression (Clynen et al., 2014; Kühne et al., 2018; Friedrich et al., 2019; Kaya et al., 2019; Weibert et al., 2019).

Abbreviations: AD, Alzheimer's disease; ANOVA, one-way analysis of variance; BDNF, brain-derived neurotrophic factor; CNS, central nervous system; CSF, cerebrospinal fluid; DA, dopamine; DOPAC, dihydroxyphenylacetic acid; EDTA, ethylene diaminetetraacetic acid; ELISA, enzyme linked immunosorbent assay; ERK, extracellular signal-regulated kinases GAPDH, glyceraldehyde-3phosphate dehydrogenase; HPLC, high-performance liquid chromatography; HVA, homovanillic acid; ICV, intra-cerebroventricular; MC4R, melanocortin 4 receptor; MPP+, 1-methyl-4-phenylpyridillium ion; MPTP, 1-methyl-4-phenyl-1, 2,3,6-tetrahydropyridine; PBS, phosphate-buffered saline; PD, Parkinson's disease; p-ERK1/2, phosphorylated ERK1/2; PFA, paraformaldehyde; ROS, reactive oxygen species; SDS-PAGE, sodium dodecyl sulfate-polyacrylamide gel electrophoresis; $\mathrm{SNpc}$, substantia nigra pars compacta; Str, striatum; TEM, transmission electron microscopy; $\mathrm{TH}$, tyrosine hydroxylase; $\mathrm{TH}(+), \mathrm{TH}$-immunoreactivity positive; i.p., intraperitoneal injection.
Özsavcí et al. (2011) were among the first to report that nesfatin1 exerts neuroprotection against subarachnoid hemorrhageinduced injury in rats by inhibiting neutrophil infiltration and the subsequent release of inflammatory mediators. Tang et al. (2012) further showed that nesfatin-1 significantly suppresses inflammation and neuronal cell apoptosis after head trauma. Our own data also demonstrate that nesfatin-1 is capable of antagonizing rotenone and 1-methyl-4-phenylpyridinium ion $\left(\mathrm{MPP}^{+}\right)$-induced neurotoxicity, and its neuroprotective effect appears to be associated with the activation of the C-Raf/extracellular signal-regulated kinase (ERK) signaling cascade, leading to reduced apoptosis caused by mitochondrial dysfunction after exposure to the neurotoxic agents rotenone and $\mathrm{MPP}^{+}$(Tan et al., 2015; Shen et al., 2017). More recently, a clinical study provided evidence that the nesfatin-1 level in the blood of PD patients is significantly lower than that in controls (Emir et al., 2019).

While our data, together with data from other groups, have established a protective function of nesfatin- 1 in the central nervous system (CNS), the receptor to which nesfatin-1 molecules bind has not yet been identified (Brailoiu et al., 2007, 2013; Shen et al., 2017). Yosten and Samson (2009) postulated that melanocortin 4 receptor (MC4R) may serve as a candidate nesfatin-1 receptor. Brailoiu et al. (2007) further speculated that the receptor of nesfatin-1 is a G-protein-coupled receptor that acts through Gi and Gs. Studies in our lab using the patch clamp technique have demonstrated that nesfatin-1 can directly decrease the excitability of nigral dopaminergic neurons in rat brain slices (Li et al., 2014), thus suggesting that the nesfatin1 receptor may be expressed in nigral dopaminergic neurons. These findings prompted us to ask whether MC4R is expressed in dopaminergic neurons in the SNpc and whether delivering SHU 9119, an MC4R inhibitor, directly to the lateral ventricle could block MC4R to affect neuronal function in the SNpc through MC4R. The synthetic peptide SHU 9119 \{sequence: Ac-Nlec[Asp-His-DNal (2')-Arg-Trp-Lys]-NH2\} has been generally used to identify the physiological role of MC4R (Hruby et al., 1995; Yang et al., 2002; Grieco et al., 2007).

Based on our own data and data in the literature, we hypothesized that MC4R, a putative nesfatin-1 receptor, is expressed in dopaminergic neurons in the SNpc. We further hypothesized that the level of nesfatin-1 in the central milieu, especially in the cerebrospinal fluid (CSF), is critical to its protective role in maintaining the normal physiological function of the nigrostriatal system. In the present study, we applied an in vivo intra-cerebroventricular (ICV) injection technique to deliver SHU 9119 or nesfatin-1 antibody directly into the lateral ventricle of the brain to observe whether neurodegeneration in the nigrostriatal system occurs as a consequence of MC4R receptor inhibition or decreased CSF nesfatin-1 levels.

\section{MATERIALS AND METHODS}

\section{Animals}

The study was conducted in compliance with standard animal use practices and was approved by the Animal Ethics Committee 
of Qingdao University (QDU20180120, Jan-2018). Thirty male C57BL/6 mice were purchased from Beijing Vital River Laboratory Animal Technology Co. (Beijing, China). The mice were maintained in a facility with a 12 -h light-dark cycle and were provided with food and water ad libitum. At the time of use, the mice were 7 weeks old and weighed 20-25 g.

\section{Experimental Design and Animal Treatment}

Two sets of experiments were designed to test our hypothesis (Figure 1). Experiment 1 was designed to identify the presence of MC4R on dopaminergic neurons in the SNpc by double staining of tyrosine hydroxylase (TH) and MC4R in brain sections of C57BL/6 mice $(n=6)$ (Figure 1A). Experiment 2 was designed to study whether the lateral ventricle administration of anti-nesfatin-1 antibody would induce nigrostriatal system degeneration in mice ( $n=24$, six mice per group) (Figure 1B). The following is the animal treatment for experiment 2 .

To embed the guide cannula into the lateral ventricle, mice were fully anesthetized with chloral hydrate $(10 \%, 10 \mathrm{~mL} / \mathrm{kg})$ (Keshi, Chengdu, China) by intraperitoneal (i.p.) injection and placed in a stereotaxic frame (RWD, Shenzhen, China). A longitudinal incision was made in the scalp to expose the surface of the skull. A cranial burr hole $(1 \mathrm{~mm})$ was drilled into the skull of the right hemisphere with the following coordinates: $0.3 \mathrm{~mm}$ posterior to bregma and $1.0 \mathrm{~mm}$ lateral to the midline (Paxinos and Franklin, 2001; Shen et al., 2017, 2020). Next, a stainless steel cannula (RWD, Shenzhen, China) was embedded at $3.2 \mathrm{~mm}$ vertical from the skull surface (Young et al., 2012). The cannula was fixed on the skull by a mixture of dental base acrylic resin powder and liquid (Pigeon Dental, Shanghai, China). On the experimental days, the dummy cannula was removed, and an injector (3.2 $\mathrm{mm}$ protrusion) was inserted into the guide cannula. ICV injection of drug solutions was performed manually at a rate of $0.5 \mu \mathrm{L} / \mathrm{min}$ (Dore et al., 2017) in freely moving animals through the cannula, which was connected to a $5 \mu \mathrm{L}$ Hamilton microsyringe (Reno, NV, United States), and the injection cannula was kept in situ for an additional $3 \mathrm{~min}$ to avoid reflux of the solution along the injector track. The ICV injection technique is well established in this lab and was used in our previous studies (Shen et al., 2017, 2020).

After 1 week of recovery, 24 mice (8 weeks old) were randomly divided into four groups (six mice per group) and administered ICV injections once per day for 14 continuous days of the following: (1) control group: $2 \mu \mathrm{L}$ saline; (2) nonimmune anti-mouse IgG antibody group (MAB 201): $2 \mu \mathrm{L}$ IgG1 $\kappa$ antibody (1.3 mg/ml) (Millipore, Darmstadt, Germany) (Evans et al., 2019); (3) MC4R receptor inhibitor group: $0.5 \mu \mathrm{L}$ SHU 9119 (0.5 nmol) (Tocris, Bristol, United Kingdom) (Leckstrom et al., 2009); and (4) anti-nesfatin-1 group: $2 \mu \mathrm{L}$ nesfatin-1 antibody $(0.12 \mathrm{mg} / \mathrm{mL})$ (Phoenix, Burlingame, CA, United States). Twenty-four hours after the last injection, the CSF sample was collected, and then the brain was removed from the skull. The right side of the SNpc was dissected to determine protein levels by Western blot or enzyme-linked immunosorbent assay (ELISA); the striatum was dissected for neurochemical analyses by high-performance liquid chromatography (HPLC). The collected samples were stored at $-80^{\circ} \mathrm{C}$ for future analyses. The left side of the brain was fixed in $4 \%$ paraformaldehyde (PFA) for immunofluorescence staining.
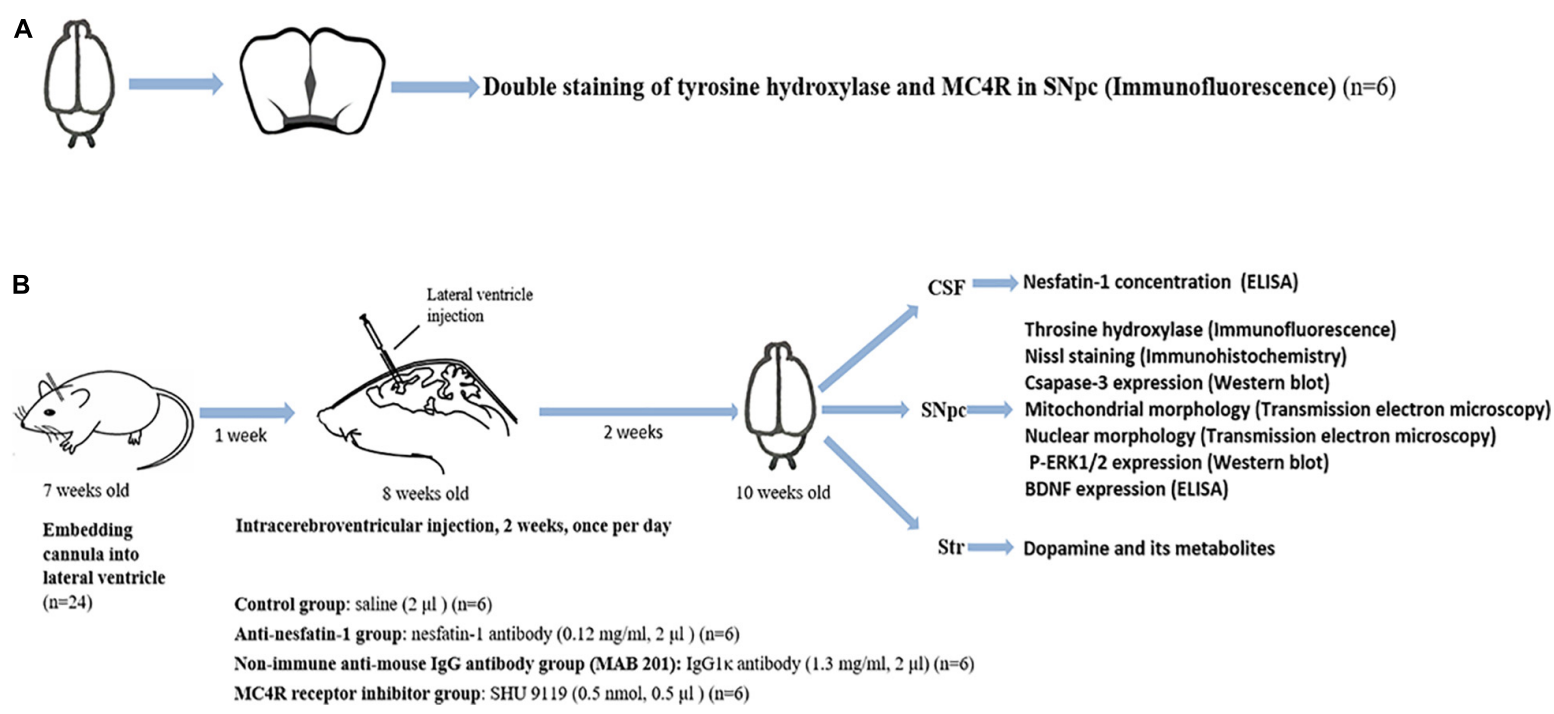

FIGURE 1 | Schematic illustration of the experimental design. (A) Double staining of TH and MC4R in the SNpc to demonstrate the presence of MC4R in the SNpc $(n=6)$. (B) Anti-nesfatin-1 antibody induces nigrostriatal system degeneration in mice $(n=24$, six mice per group). The mice received the substances at the doses indicated by ICV injection for 14 days. The CSF was collected for the determination of the nesfatin-1 concentration. The SNpc and striatum were collected for the determination of $\mathrm{TH}$, caspase-3, and $p$-ERK1/2 expression, BDNF concentration, mitochondrial morphology, and nuclear morphology. BDNF, brain-derived neurotrophic factor; CSF, cerebrospinal fluid; ELISA, enzyme-linked immunosorbent assay; MAB 201, non-immune anti-mouse IgG antibody; MC4R, melanocortin 4 receptor; $p$-ERK1/2, phosphorylated ERK1/2; SHU 9119, MC4R receptor inhibitor; SNpc, substantia nigra pars compacta; Str, striatum; TH, tyrosine hydroxylase; $\mathrm{ICV}$, intra-cerebroventricular. 


\section{Double Staining of TH and MC4R in the SNpc}

This experiment was conducted to identify the presence of MC4R on dopaminergic neurons in the SNpc. Untreated mice (8 weeks old, $n=6)$ were fully anesthetized with chloral hydrate $(10 \%$, $10 \mathrm{~mL} / \mathrm{kg}$, i.p.) (Keshi, Chengdu, China). Brains of C57BL/6 mice were removed from the skull, fixed in $4 \% \mathrm{PFA}$ for $72 \mathrm{~h}$ at $4^{\circ} \mathrm{C}$, incubated in $0.1 \mathrm{mmol} / \mathrm{L}$ phosphate buffer ( $\mathrm{pH} 7.4$ ) containing $25 \%$ sucrose at $4^{\circ} \mathrm{C}$ for $2-3$ days, and then stored at $-80^{\circ} \mathrm{C}$. The frozen brain tissues were cut into $20-\mu \mathrm{m}$-thick sections. Double immunofluorescence staining is routinely performed in our laboratory (Zhang et al., 2014; Shen et al., 2017). The freefloating brain sections were incubated with $0.3 \%$ Triton X-100 diluted in PBS for $2 \mathrm{~h}$ at room temperature for permeabilization and blocked in normal goat serum for $1 \mathrm{~h}$ at room temperature. The sections were then double-immunostained at $4^{\circ} \mathrm{C}$ with primary antibodies against TH $(1: 2,000)$ (Millipore, Darmstadt, Germany) and MC4R (1:50) (Alomone Labs, Jerusalem, Israel) for $24 \mathrm{~h}$ followed by incubation with goat anti-rabbit Alexa 488-conjugated secondary antibody (1:800) (Abcam, Cambridge, United Kingdom) and goat anti-mouse Texas Red secondary antibody (1:800) (Birmingham, AL, United States) at room temperature for $2 \mathrm{~h}$. The brain tissues were mounted on objective slides using ProLong Gold Anti-fade Mountant (Cell Signaling, Boston, MA, United States) to avoid fluorescence bleaching. The negative control was established by using only the secondary antibody to show non-specific background staining. Images were obtained by immunofluorescence microscopy (Observer A1, Zeiss, Germany) at a magnification of $400 \times$.

\section{CSF Collection}

Cerebrospinal fluid samples were collected using a 28G butterfly needle connected to a 1-mL syringe. After being anesthetized with chloral hydrate $(10 \%, 10 \mathrm{~mL} / \mathrm{kg}$, i.p.) (Keshi, Chengdu, China), the surface of the mouse brain was held vertically on the work surface, and the needle was inserted vertically (relative to the work surface) between the protuberance and the spine of the atlas. After a puncturing sensation was felt, the CSF was slowly collected (Gu et al., 2012).

\section{Quantification of Nesfatin-1 in the CSF by ELISA}

Cerebrospinal fluid samples from six mice per group were collected for ELISA. CSF samples $(10 \mu \mathrm{L})$ were diluted 1:20 with artificial CSF (a buffer containing $103 \mathrm{mmol} / \mathrm{L} \mathrm{NaCl}, 4.7 \mathrm{mmol} / \mathrm{L}$ $\mathrm{KCl}, 1.2 \mathrm{mmol} / \mathrm{L} \mathrm{KH} 2 \mathrm{PO} 4,1.2 \mathrm{mmol} / \mathrm{L} \mathrm{MgSO} 4,25 \mathrm{mmol} / \mathrm{L}$ $\mathrm{NaHCO} 3,10 \mathrm{mmol} / \mathrm{L}$ glucose, $1 \mathrm{mmol} / \mathrm{L}$ sodium pyruvate, and $2.5 \mathrm{mmol} / \mathrm{L} \mathrm{CaCl}$, pH 7.4) (Shen et al., 2020). Concentrations of nesfatin-1 in the CSF were determined by a mouse nesfatin1 ELISA kit from JianglaiBIO (Beijing, China) according to the manufacturer's instructions (Zhang et al., 2018).

\section{Immunofluorescence Staining of TH in the SNpc}

Tyrosine hydroxylase is a rate-limiting enzyme in the synthesis process of dopamine and norepinephrine
(Moore and Bloom, 1979). It is abundantly expressed in dopaminergic neurons (Raisman-Vozari et al., 1991; Blanchard et al., 1993). The protocol for immunofluorescence staining of $\mathrm{TH}$ is routinely used in our laboratory (Jiang et al., 2008; Shen et al., 2017). Brains were fixed in 4\% PFA for $72 \mathrm{~h}$ at $4^{\circ} \mathrm{C}$ then incubated in $0.1 \mathrm{~mol} / \mathrm{L}$ phosphate buffer $(\mathrm{pH} 7.5)$ containing $25 \%$ sucrose at $4^{\circ} \mathrm{C}$ for $2-3$ days. The frozen brain tissues were cut into 20 - $\mu \mathrm{m}$-thick sections. The brain tissue sections were used for immunofluorescence staining of $\mathrm{TH}$ in the SNpc. The free-floating sections were first incubated with $0.1 \%$ Triton X-100 and goat serum (Gibco-BRL, Grand Island, NY, United States) in phosphate-buffered saline (PBS) for $2 \mathrm{~h}$ and then incubated overnight at $4^{\circ} \mathrm{C}$ with the $\mathrm{TH}$ primary antibody $(1: 1,000)$ (Millipore, Burlington, MA, United States) in PBS containing $0.1 \%$ Triton X-100 (St. Louis, MO, United States). The sections used for staining $\mathrm{TH}$ in the SNpc were incubated with Alexa Fluor 555-conjugated donkey anti-rabbit secondary antibody (Abcam, Cambridge, United Kingdom), and images were obtained by immunofluorescence microscopy (Observer A1, Zeiss, Germany) at magnifications of $100 \times$ and $400 \times$.

\section{NissI Staining in the SNpc}

Brain sections $(20 \mu \mathrm{m})$ were stained with Nissl staining reagent (Beyotime, Shanghai, China) for 20-30 min and then rinsed with double-distilled water for $5 \mathrm{~min}, 70 \%$ ethanol solution for $5 \mathrm{~s}$, and $95 \%$ ethanol solution for $5 \mathrm{~s}$. Then, the brain sections were dehydrated in anhydrous ethanol, cleared with xylene solution (Sinopharm, Shanghai, China), and mounted with neutral gum (Yiyang, Shanghai, China) (Jyothi et al., 2015; Fathalla et al., 2017).

\section{Stereological Analysis}

Total numbers of TH-positive and Nissl-positive neurons were estimated bilaterally from every 4 th section through the extent of the SNpc of each brain. Stereology was performed at $400 \times$ using an Axioplan 2 imaging microscope (Zeiss, Göttingen, Germany) fitted with a DEI-750 CE video camera (Optronics, CA, United States) and a LEP MAC5000 motorized stage controller (Ludl Electronic Products, NY, United States). The software package used was Stereo Investigator (MBF Bioscience, VT, United States). The coefficient of error for the individual counts was 0.01 . A counting frame of $50 \mu \mathrm{m} \times 50 \mu \mathrm{m}$ and a height of $10 \mu \mathrm{m}$ was chosen. Only the neurons within the counting frame were counted. At least 50 markers were counted within 50 framing sites for each mouse. The neuron count multiplied by four was used as the final number of $\mathrm{TH}+$ cells. Data are expressed as $\mathrm{TH}(+)$-dopaminergic neurons/SNpc (Healy-Stoffel et al., 2012; Park et al., 2012; Nam et al., 2015; Shen et al., 2017; Peng et al., 2018).

\section{Quantification of Dopamine and Its Metabolite Levels by HPLC}

The HPLC protocol has been well established and is routinely used in our laboratory (Jiang et al., 2008; Shen et al., 2017). Samples of the striatum were weighed and then homogenized in $120 \mu \mathrm{L}$ of solution A (0.4 M perchloric acid). After initial 
centrifugation $\left(12,000 \mathrm{rpm}\right.$ for $20 \mathrm{~min}$ at $4^{\circ} \mathrm{C}$ ) (Eppendorf 5810R, Germany), $80 \mu \mathrm{L}$ of the supernatant was transferred into Eppendorf tubes, and $40 \mu \mathrm{L}$ of solution B [containing $20 \mathrm{mM}$ citromalic acid potassium, $300 \mathrm{mM}$ dipotassium phosphate, $2 \mathrm{mM}$ ethylenediamine tetraacetic acid (EDTA) $2 \mathrm{Na}$ ] was added. After additional centrifugation (12,000 rpm for $20 \mathrm{~min}$ at $4^{\circ} \mathrm{C}$ ), $100 \mu \mathrm{L}$ of the supernatant was assayed for dopamine (DA) and its metabolites homovanillic acid (HVA) and dihydroxyphenylacetic acid (DOPAC) by HPLC. Separation was achieved on an Agilent $\mathrm{C} 18$ reverse-phase column $(4.6 \mathrm{~mm} \times 150 \mathrm{~mm} \times 5 \mu \mathrm{m})$ (Agilent, CA, United States). The mobile phase consisted of $20 \mathrm{mM}$ citromalic acid, $50 \mathrm{mM}$ sodium caproate, $0.134 \mathrm{mM}$ EDTA.2Na, $3.75 \mathrm{mM}$ sodium octane sulfonic acid, and $1 \mathrm{mM}$ di-secbutylamine in $5 \%(\mathrm{v} / \mathrm{v})$ methanol; the flow rate was $1 \mathrm{~mL} / \mathrm{min}$. A 2,465 electrochemical detector (Waters, United States) was operated in screen mode. The results are expressed as $\mathrm{ng} / \mathrm{mg}$ wet weight of brain tissue.

\section{Western Blot}

Samples of the SNpc were lysed in RIPA lysis buffer containing protease inhibitor and phosphatase inhibitor cocktail (Beyotime, Shanghai, China). The protein concentration was determined using BCA kits (Beyotime, Shanghai, China) (Zhang et al., 2020). For Western blotting, the samples were boiled in $5 \times$ loading buffer (Applygen, Beijing, China), electrophoresed on a 12\% Tris-glycine gel by sodium dodecyl sulfate-polyacrylamide gel electrophoresis (SDS-PAGE) and then transferred to polyvinylidene fluoride membranes with a pore size of $0.45 \mu \mathrm{m}$ (Merck Millipore, MA, United States) (Schägger, 2006). After blocking with $7 \%$ non-fat milk at room temperature for $2 \mathrm{~h}$, the membranes were incubated for $24 \mathrm{~h}$ with primary antibody overnight at $4^{\circ} \mathrm{C}$ and then with secondary antibodies coupled to horseradish peroxidase for $2 \mathrm{~h}$. The following primary antibodies purchased from Cell Signaling Technology (Boston, MA, United States) were used for Western blot analysis: phospho-ERK1/2 (1:1,000), caspase-3 (1:1,000), and glyceraldehyde-3-phosphate dehydrogenase (GAPDH) $(1: 1,000)$. The following secondary antibodies were used for Western blot analysis: anti-rabbit IgG-HRP (1:10,000) and anti-mouse IgG-HRP (1:10,000) (Santa Cruz Biotechnology, Dallas, TX, United States). Cross-reactivity was visualized using ECL Western blot detection reagents (Millipore, Burlington, MA, United States), analyzed by scanning densitometry using UVP VisionWorks ${ }^{\text {TM }}$ LS Software (UVP, Cambridge, United Kingdom) and quantified with ImageJ Software (Zhang et al., 2020).

\section{Morphological Examination of Mitochondria and Nuclei by Transmission Electron Microscopy}

The subcellular microstructure was examined by using a JEOL JEM-1400 transmission electron microscope (JEOL, Tokyo, Japan) at the Electron Microscopy Core Facility at Qingdao University. SNpc samples were cut into $2 \mathrm{~mm}^{3}$ pieces, fixed with $2.5 \%$ glutaraldehyde for more than $4 \mathrm{~h}$, postfixed with $2 \%$ osmium tetroxide in Sorensen's buffer for $1 \mathrm{~h}$, dehydrated in an ascending ethanol series (30, 50, 70, 80, 90, 95, and 100\%), and embedded in Epon/Araldite resin. Thin sections $(70 \mathrm{~nm})$ were cut using a Leica EM UC7 Ultramicrotome (Leica Microsystems, Wetzlar, Germany) and placed on 100 mesh copper grids (Electron Microscopy Sciences, Hatfield, PA, United States). Sample grids were poststained with premixed solutions of uranyl acetate and lead citrate (Ultrostain I and II, respectively, Leica Microsystems, Wetzlar, Germany) and examined at $80 \mathrm{kV}$ using a JEOL JEM-1400 transmission electron microscope (JEOL, Tokyo, Japan) (Eustaquio et al., 2018).

For animals in each group ( $n=6$ per group), at least three samples per animal were prepared. Images were captured of randomly selected neurons (approximately 10 neurons per animal) from all the animals in each group. The images were recorded using a TVIPS F416 4k $\times 4 \mathrm{k}$ CCD camera running EM-MENU 4.0 acquisition software (Tietz Video and Image Processing Systems, Gauting, Germany). Mitochondrial length (along the long axis) and the number of perinuclear mitochondria were counted and summarized from 10 images for each animal. The nuclear morphology of dopaminergic neurons was also observed and described (Eustaquio et al., 2018).

\section{Quantification of Brain-Derived Neurotrophic Factor in the SNpc by ELISA}

Samples of SNpc were lysed in RIPA lysis buffer containing protease inhibitor and phosphatase inhibitor cocktail (Beyotime, Shanghai, China). The protein concentration was determined using BCA kits (Beyotime, Shanghai, China). The samples were then diluted 1:10 with sample dilution buffer (1\% BSA with $0.05 \%$ Tween-20). The brain-derived neurotrophic factor (BDNF) concentration was determined by the Total BDNF Quantikine ELISA Kit from R\&D Systems (MN, United States) according to the manufacturer's instructions (Polacchini et al., 2015).

\section{Statistical Analysis}

SPSS 20.0 (SPSS Inc., Chicago, IL, United States) was used to analyze the data. All data are shown as the mean $\pm \mathrm{SD}$. Differences between the means of two groups were compared using the unpaired-samples $t$-test. One-way analysis of variance (ANOVA) followed by the Student-Newman-Keuls test was used to compare differences between means in more than two groups. $p<0.05$ was considered statistically significant.

\section{RESULTS}

\section{Expression of MC4R in Dopaminergic Neurons in the SNpc}

Tyrosine hydroxylase is typically expressed in dopaminergic neurons (Pickrell et al., 2015; Shehadeh et al., 2019). A double staining technique was used to detect the expression of MC4R in dopaminergic neurons in the SNpc. The images in Figure 2 illustrate the robust signal of the MC4R staining in the SNpc. The MC4R signals were colocalized with $\mathrm{TH}$ signals, indicating the presence of MC4R in dopaminergic neurons in the SNpc. 

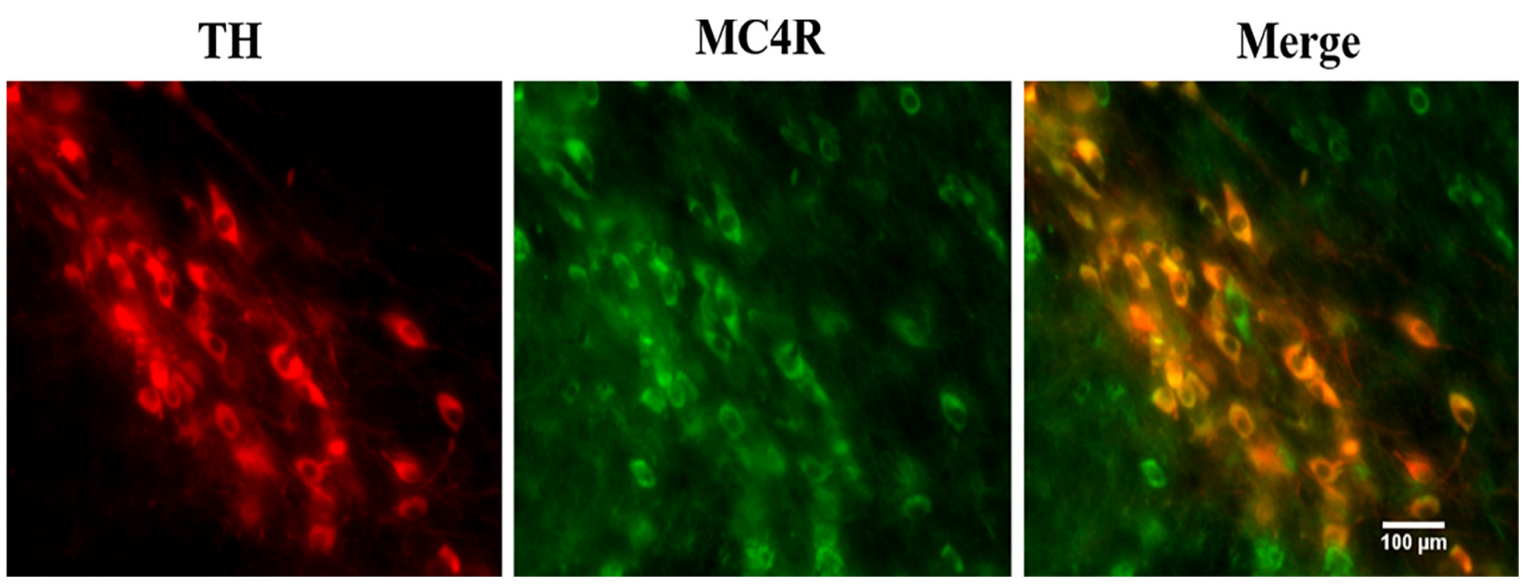

FIGURE 2 | Double staining of TH and MC4R in the mouse SNpc $(n=6)$. The images were obtained by immunofluorescence microscopy. TH, tyrosine hydroxylase; MC4R, melanocortin 4 receptor; SNpc, substantia nigra pars compacta.

\section{Decreased Nesfatin-1 Levels in CSF Following Daily ICV Injection of Anti-nesfatin-1 Antibody}

Following the various ICV treatments, we used ELISA to quantify the concentration of nesfatin-1 in the CSF. The data presented in Table 1 show that daily ICV injection of saline, nonimmune anti-mouse IgG antibody, MC4R receptor inhibitor (SHU 9119), and anti-nesfatin-1 antibody for 14 days resulted in nesfatin-1 concentrations in the CSF of $0.29 \pm 0.083$, $0.33 \pm 0.019,0.31 \pm 0.065$, and $0.02 \pm 0.010 \mathrm{ng} / \mathrm{mL}$, respectively. Treatment with anti-nesfatin-1 antibody significantly decreased the nesfatin-1 level in the CSF compared to the control treatment (by $93.1 \%$ ), non-immune anti-mouse IgG antibody treatment, and MC4R receptor inhibitor treatment $(p<0.05)$.

\section{ICV Injection of Anti-nesfatin-1 Antibody Induced Dopaminergic Neuron Loss in the SNpc}

After 14 days of daily ICV injection, the numbers of $\mathrm{TH}$ immunopositive $(\mathrm{TH}+)$ dopaminergic neurons in the $\mathrm{SNpc}$

TABLE 1 | Nesfatin-1 concentrations in the CSF with or without direct injection of antibody or inhibitor into the lateral ventricle.

\begin{tabular}{|c|c|c|}
\hline Group & Drug & $\begin{array}{l}\text { Nesfatin-1 concentration } \\
\text { (ng/ml) }\end{array}$ \\
\hline Control & Saline & $0.29 \pm 0.083$ \\
\hline $\begin{array}{l}\text { Anti-nesfatin-1 } \\
\text { antibody }\end{array}$ & $2 \mu l$ nesfatin-1 $(0.12$ mg/ml) & $0.02 \pm 0.010^{\star}$ \\
\hline $\begin{array}{l}\text { Non-immune } \\
\text { anti-mouse lgG } \\
\text { antibody }\end{array}$ & $\begin{array}{c}2 \mu \mathrm{l} \operatorname{lgG} 1 \kappa \text { antibody } \\
(1.3 \mathrm{mg} / \mathrm{ml})\end{array}$ & $0.33 \pm 0.019$ \\
\hline $\begin{array}{l}\text { MC4R receptor } \\
\text { inhibitor }\end{array}$ & 0.5 ul SHU 9119 (0.5 nmol) & $0.31 \pm 0.065$ \\
\hline
\end{tabular}

The drugs were administered to mice by ICV injection once daily for 14 days. The data represent the mean $\pm S D$. $n=6$ per group. ${ }^{*} p<0.05$, compared to the controls. MC4R, Melanocortin 4 receptor. in the control group, non-immune anti-mouse IgG antibody group, MC4R receptor inhibitor group, and anti-nesfatin-1 group were $4,736 \pm 702.73,5,200 \pm 72.32,4,336 \pm 168.57$, and $3,632 \pm 372.84$, respectively. Direct injection of anti-nesfatin1 antibody into the brain ventricle resulted in a significant loss of $\mathrm{TH}(+)$-dopaminergic neurons in the SNpc (Figures 3A,B). The survival ratio of $\mathrm{TH}(+)$-dopaminergic neurons in the $\mathrm{SNpc}$ in the anti-nesfatin-1 group decreased by $23 \%$ compared to that in the control group $(p<0.05)$ and by $30 \%$ compared to that in the non-immune anti-mouse IgG antibody group (MAB 201 group) $(p<0.05)$. In the MC4R receptor inhibitor (SHU 9119)-treated group, there was no significant reduction in the number of dopaminergic neurons compared with that in the control group.

After 14 days of daily ICV injection, the numbers of Nisslpositive neurons in the $\mathrm{SNpc}$ in the control group, non-immune anti-mouse IgG antibody group, MC4R receptor inhibitor group, and anti-nesfatin-1 group were 5,638 $\pm 132.94,6,210 \pm 698.62$, $6,295 \pm 94.75$, and 4,562 \pm 79.37 , respectively. Direct injection of anti-nesfatin-1 antibody into the brain ventricle resulted in a significant loss of Nissl-positive neurons in the SNpc (Figures 3C,D). The survival ratio of Nissl-positive neurons in the SNpc in the anti-nesfatin-1 group decreased by $19 \%$ compared to that in the control group $(p<0.05)$ and by $26.5 \%$ compared to that in the non-immune anti-mouse IgG antibody group (MAB 201 group) $(p<0.05)$.

\section{ICV Injection of Anti-nesfatin-1 Antibody Induced Depletion of Dopamine and Its Metabolites in the Striatum}

After 14 days of daily treatments, the levels of DA and its metabolite HVA were significantly decreased in the striatum in the anti-nesfatin-1 group. Anti-nesfatin-1 antibody treatment resulted in 28, 22, and 29\% depletion of DA compared to its levels in the control, non-immune anti-mouse IgG antibody, and MC4R receptor inhibitor groups $(p<0.05)$, respectively (Figure 4A). Anti-nesfatin-1 treatment caused 

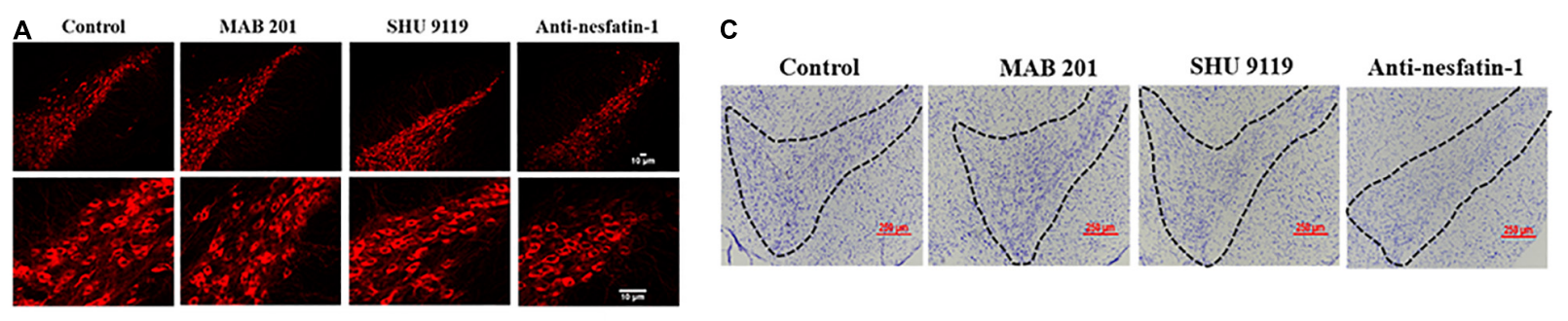

B
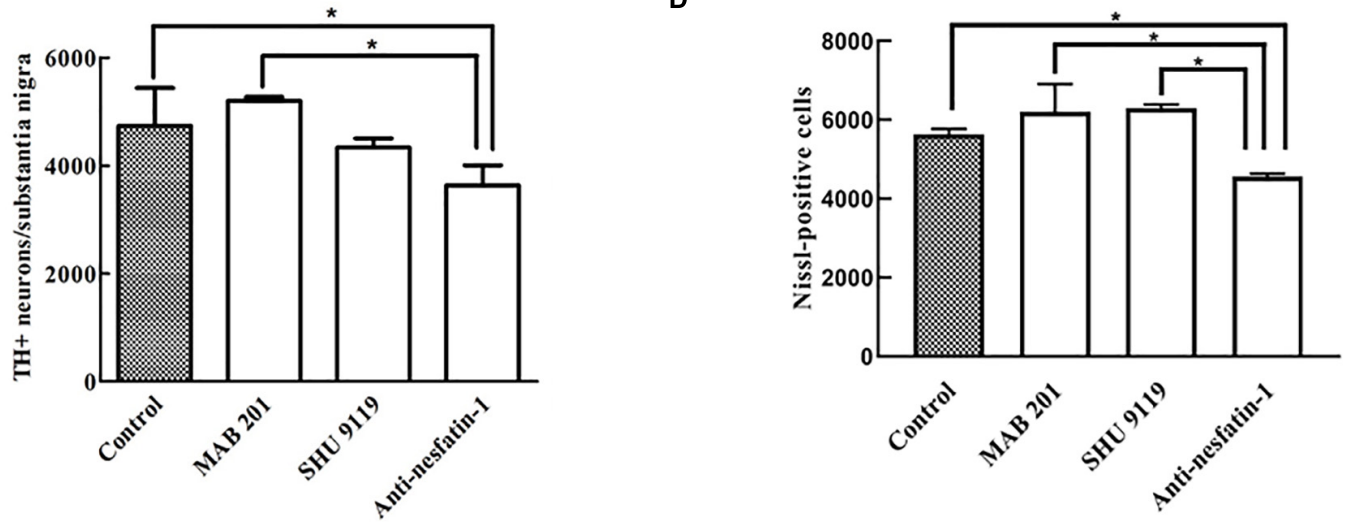

FIGURE 3 | Anti-nesfatin-1 treatment induced nigral dopaminergic neuron degeneration. (A) TH(+)-dopaminergic neurons in the SNpc of control mice and mice treated with MAB 201, SHU 9119, or anti-nesfatin-1 antibody are shown. (B) A summary of the data showing the numbers of TH(+)-dopaminergic neurons in the different groups (TH, tyrosine hydroxylase). (C) Nissl-positive neurons in control mice and mice treated with MAB 201, SHU 9119 or anti-nesfatin-1 antibody are shown. The dotted portion indicates the SNpc. (D) A summary of the data showing the numbers of Nissl-positive neurons in the different groups. Each value represents the mean $\pm \mathrm{SD}, n=6$; * $p$ <.05. MAB 201, non-immune anti-mouse IgG antibody; SHU 9119, MC4R receptor inhibitor; SNpc, substantia nigra pars compacta; $\mathrm{TH}(+)$, TH-positive.
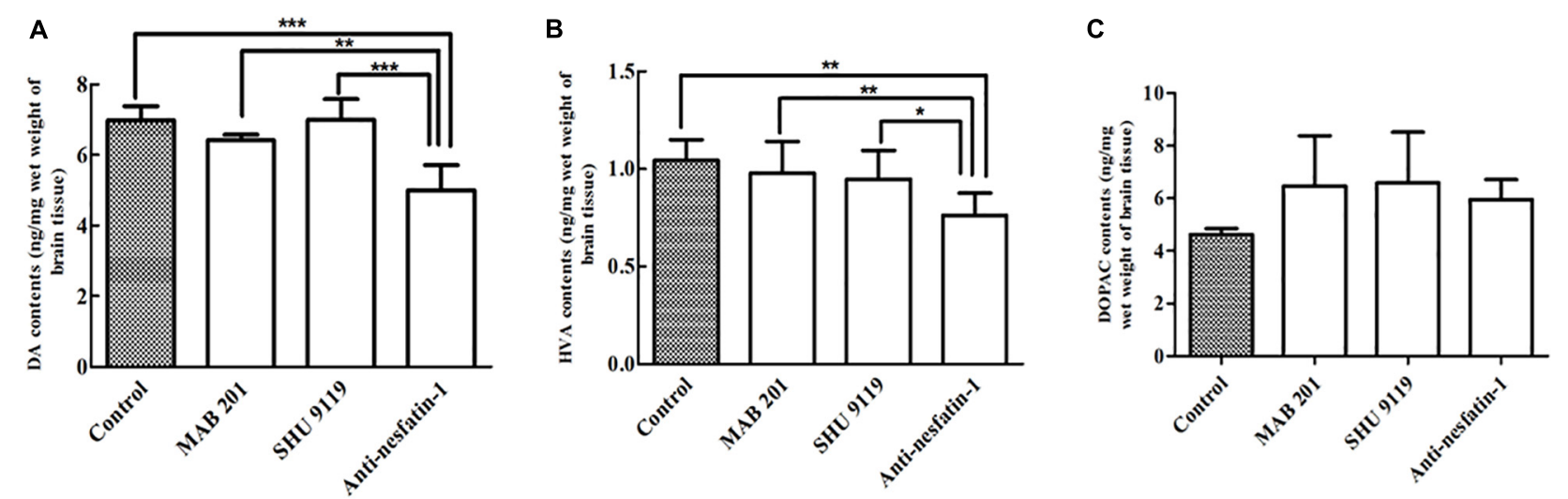

FIGURE 4 | Anti-nesfatin-1 antibody-induced depletion of DA and HVA in the striatum of the right brain $(n=6)$. (A) Striatal DA levels in control mice and mice treated with MAB 201, SHU 9119, or anti-nesfatin-1 antibody are shown. (B) Striatal HVA levels in the different groups. (C) Striatal DOPAC levels in the different groups (DA, dopamine; HVA, homovanillic acid; DOPAC, dihydroxyphenylacetic acid). Each value represents the mean $\pm \mathrm{SD}, n=6$; ${ }^{\star \star *} p<0.0001$, ${ }^{\star \star} p<0.005$, and ${ }^{\star} p<0.05$. MAB 201, non-immune anti-mouse IgG antibody; SHU 9119, MC4R receptor inhibitor.

26, 22, and 19\% depletion of HVA, respectively, compared to its level in these groups $(p<0.05)$ (Figure 4B). The DA and HVA levels in mice pretreated with MAB 201 and SHU 9119 did not significantly change compared with those in the control mice (Figures $4 \mathbf{A}, \mathbf{B}$ ). No significant difference was found in DOPAC levels among all the treatment groups (Figure 4C).

\section{Anti-nesfatin-1 Antibody Treatment Stimulated Caspase-3 Expression in the SNpc}

Caspase-3 activation is a recognized marker of cell apoptosis (Rogers et al., 2017). The Western blot data in Figure 5A show that ICV injection of the anti-nesfatin-1 antibody increased the 


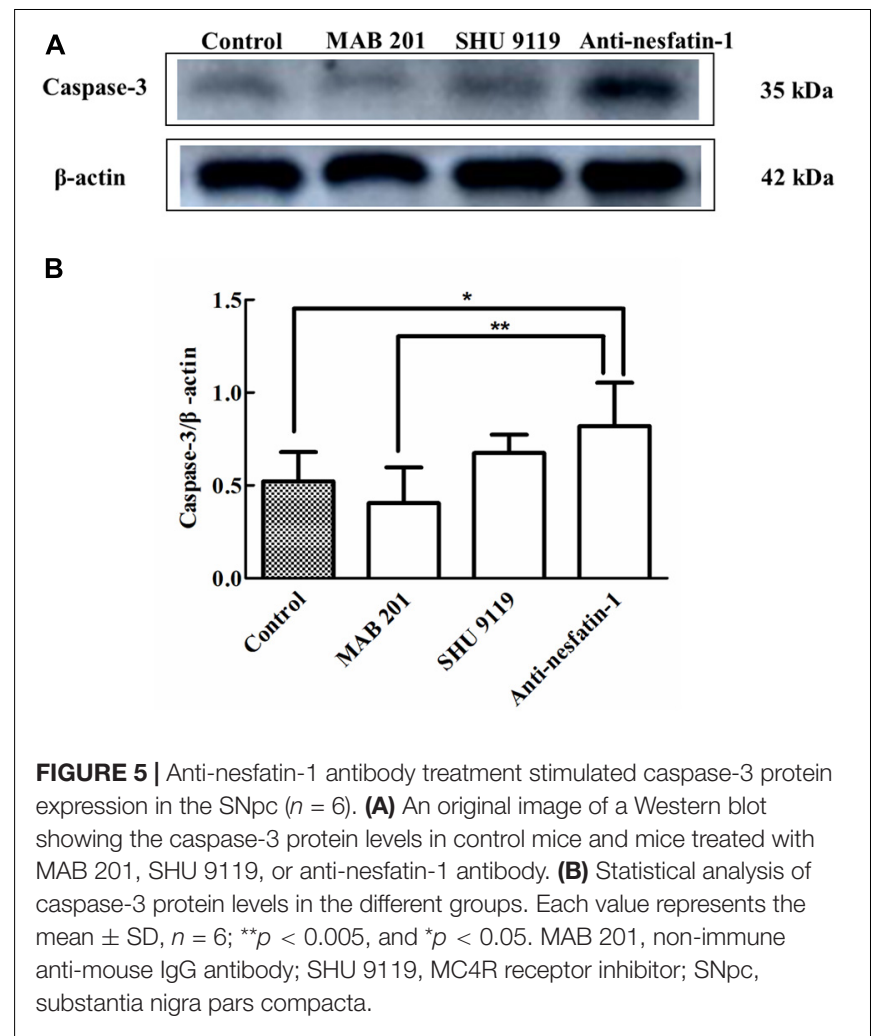

expression of caspase-3. After 14 days of daily ICV injection, the ratios of caspase- $3 / \beta$-actin expression in the $\mathrm{SNpc}$ in the control group, non-immune anti-mouse IgG antibody group, MC4R receptor inhibitor group, and anti-nesfatin-1 group were $0.522 \pm 0.177,0.405 \pm 0.215,0.740 \pm 0.069$, and $0.817 \pm 0.260$, respectively. The ratios of caspase- $3 / \beta$-actin expression demonstrated that the anti-nesfatin-1 antibody treatment increased caspase- 3 expression by $57 \%$ compared to the control treatment $(p<0.05)$ (Figure 5B). Furthermore, the expression of caspase- 3 in the anti-nesfatin-1 group was increased by $102 \%$ compared to that in the non-immune antimouse IgG antibody group $(p<0.05)$ (Figure 5B). These data indicate a statistically significant upregulation of caspase-3 expression, an indicator of induced cell apoptosis, in the SNpc of mice following the reduction of nesfatin-1 in the CSF.

\section{ICV Injection of Anti-nesfatin-1 Antibody Induced Mitochondrial Lesions and Nuclear Shrinkage in the SNpc}

Altered cell apoptosis could be due to dysfunctional mitochondria in neuronal cells (Nunnari and Suomalainen, 2012; Perier et al., 2012; Franco-Iborra et al., 2016). We used transmission electron microscopy (TEM) to examine mitochondrial morphology. The data in Figure 6A show a marked reduction in mitochondrial numbers in dopaminergic neurons in the SNpc after daily ICV treatment with anti-nesfatin1 antibody for 14 days. Compared with the control treatment, treatment with anti-nesfatin-1 resulted in a $54 \%$ depletion of the number of mitochondria (Figure 6B).
We further examined nuclei in dopaminergic neurons by TEM. The volume of the nucleus in the anti-nesfatin-1 group was significantly reduced; the edges of the nucleus were also visibly folded inward, suggesting that the nuclei of dopaminergic neurons were impaired following anti-nesfatin-1 treatment (Figure 6C). Additionally, there was a 9\% decrease in the length of the mitochondrial major axis (Figure 6D) in the anti-nesfatin1 group compared to that in the control group $(p<0.05)$.

\section{ICV Administration of Anti-nesfatin-1 Antibody Stimulated ERK1/2 Expression in the SNpc}

Phosphorylation of ERK1/2 is known to activate apoptotic factors within downstream apoptotic pathways, leading to neuronal apoptosis (Jiang et al., 2000). The Western blot data in Figure 7A show that the expression of $p$-ERK1/2 was noticeably increased following anti-nesfatin-1 treatment. After 14 days of treatment, the ratios of $p$-ERK/ $\beta$-actin in the $\mathrm{SNpc}$ in the control group, non-immune anti-mouse IgG antibody group, MC4R receptor inhibitor group, and anti-nesfatin-1 group were $0.766 \pm 0.86$, $0.827 \pm 0.21,0.900 \pm 0.09$, and $1.105 \pm 0.17$, respectively (Figure 7B). The $p$-ERK level in the anti-nesfatin-1 group increased by $44 \%$ compared with that in the control group $(p<0.05)$. The $p$-ERK level in the anti-nesfatin-1 group increased by $34 \%$ compared to that in the non-immune antimouse IgG antibody group. These differences were statistically significant $(p<0.05)$.

\section{Anti-nesfatin-1 Antibody Treatment Upregulated BDNF Expression in the SNpc}

Brain-derived neurotrophic factor is a small-molecule protein structurally related to nerve growth factor that plays an important role in the growth, development, differentiation, maintenance, and regeneration of various types of neurons in the CNS (Allen et al., 2013). ELISA was used to quantify BDNF levels in the SNpc, and as shown in Figure 8, our data demonstrated that after 14 days of treatment, the concentrations of BDNF in the SNpc in the control group, non-immune anti-mouse IgG antibody group, MC4R receptor inhibitor group, and anti-nesfatin-1 group were $0.911 \pm 0.17,1.325 \pm 0.29,0.991 \pm 0.33$, and $1.873 \pm 0.32 \mathrm{pg} / \mu \mathrm{g}$ protein, respectively. A significant increase in the BDNF level in the anti-nesfatin-1 group (by $89 \%$ ) compared to that in the control group was observed $(p<0.05)$. Similar increases were also observed by comparing the anti-nesfatin-1 group with the non-immune anti-mouse IgG antibody group (41\%) and the MC4R receptor inhibitor group (89\%); these differences were all statistically significant $(p<0.05)$.

\section{DISCUSSION}

The results presented in this study establish that (1) MC4R, a putative nesfatin-1 receptor, is expressed in dopaminergic neurons in the mouse SNpc; (2) daily ICV injection of nesfatin1 antibody greatly reduces nesfatin-1 levels in the CSF; (3) 


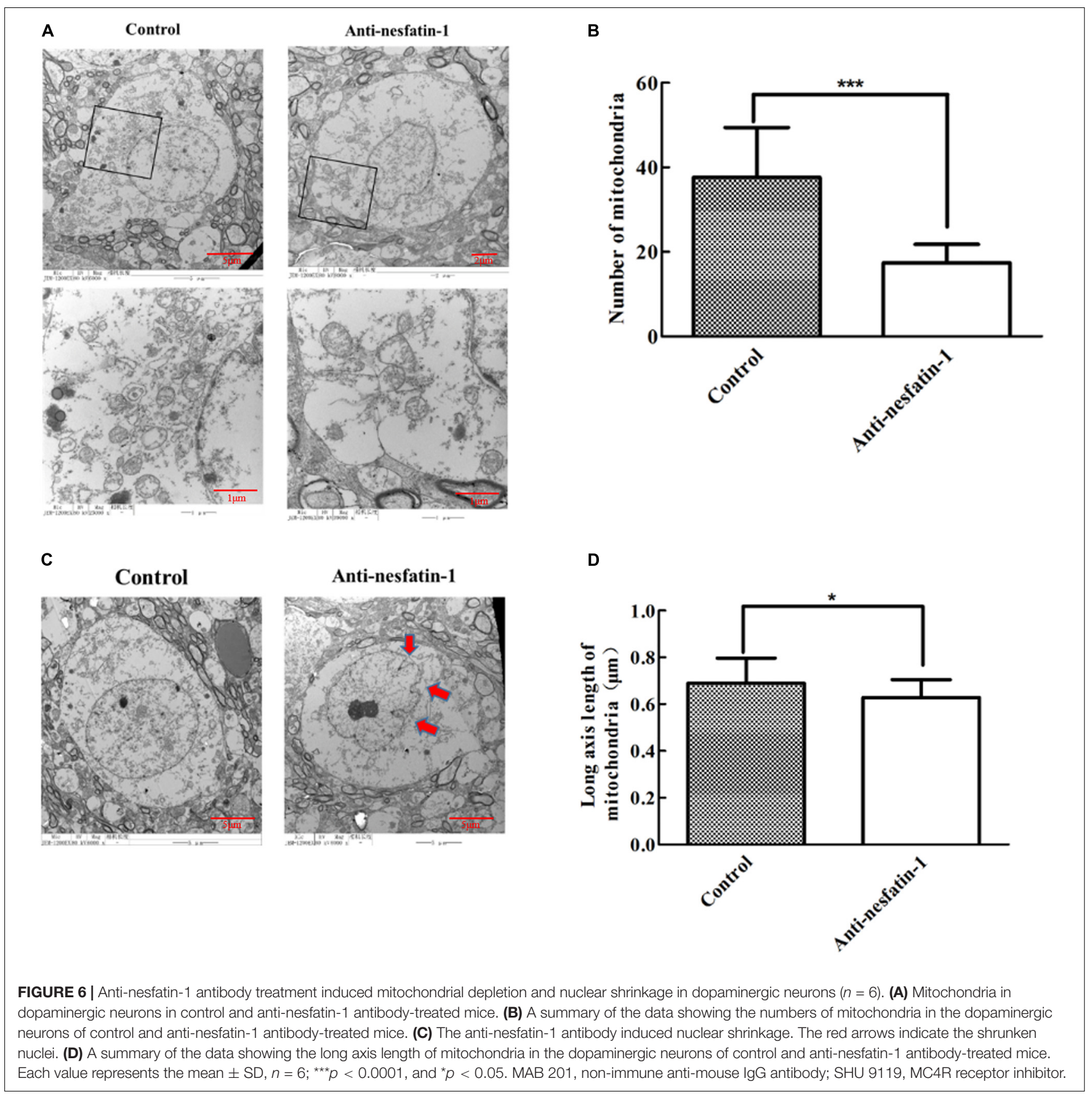

a reduced nesfatin-1 level in the CSF is associated with nigrostriatal dopaminergic system degeneration, as evidenced by the reduction in $\mathrm{TH}(+)$ neurons, altered DA neurotransmitter levels, and impaired mitochondria and nuclei in the SNpc; and (4) the mechanism underlying DA neuron damage could involve dysfunctional apoptosis. Taking into account the existing evidence in the literature, i.e., the nesfatin-1-mediated rescue of rotenone-induced cell apoptosis in dopaminergic cells (Tan et al., 2015) and MPTP-induced dopaminergic neuron loss in the SNpc (Shen et al., 2017), as well as the reduced nesfatin-1 blood levels in PD patients (Emir et al., 2019), we postulate that the brain peptide nesfatin-1 plays a critical role in maintaining the normal function of the nigrostriatal dopaminergic system.

The main pathological characteristic of $\mathrm{PD}$ is the selective loss of $\mathrm{TH}(+)$-dopaminergic neurons in the $\mathrm{SNpc}$, which results in a decrease in the number of nerve fibers projecting from the substantia nigra to the striatum and a subsequent reduction in the release of dopamine from the striatum (Daubner et al., 2011; Alieva et al., 2018). The current study demonstrates that diminished nesfatin-1 in the CSF seems likely to be responsible for dopaminergic neuron degeneration. This statement is supported by the following observations. First, reducing the 


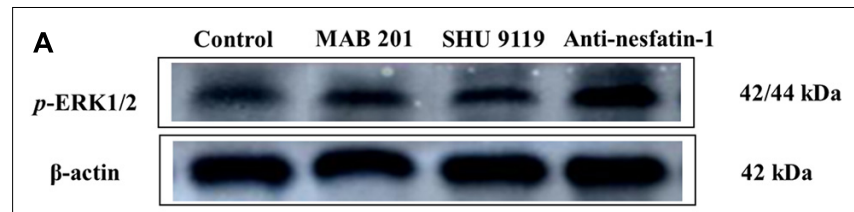

B

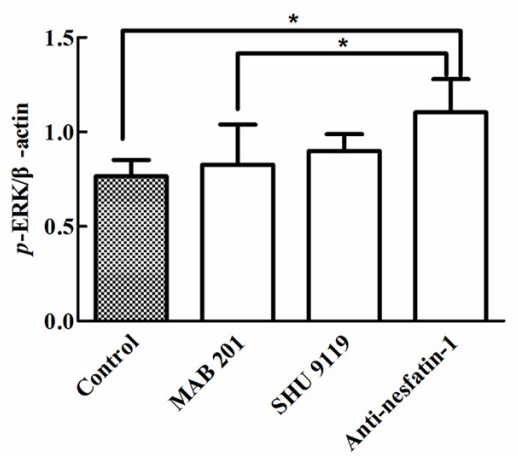

FIGURE 7 | Anti-nesfatin-1 antibody treatment induced an increase in p-ERK protein levels $(n=6)$. (A) An original image of a Western blot showing the $p$-ERK protein levels in control mice and mice treated with MAB 201, SHU 9119 or anti-nesfatin-1 antibody. (B) Statistical analysis of $p$-ERK protein levels in the different groups. Each value represents the mean $\pm \mathrm{SD}, n=6$; ${ }^{*} p<0.05$. MAB 201, non-immune anti-mouse IgG antibody; SHU 9119, MC4R receptor inhibitor; $p$-ERK, phosphorylated ERK.

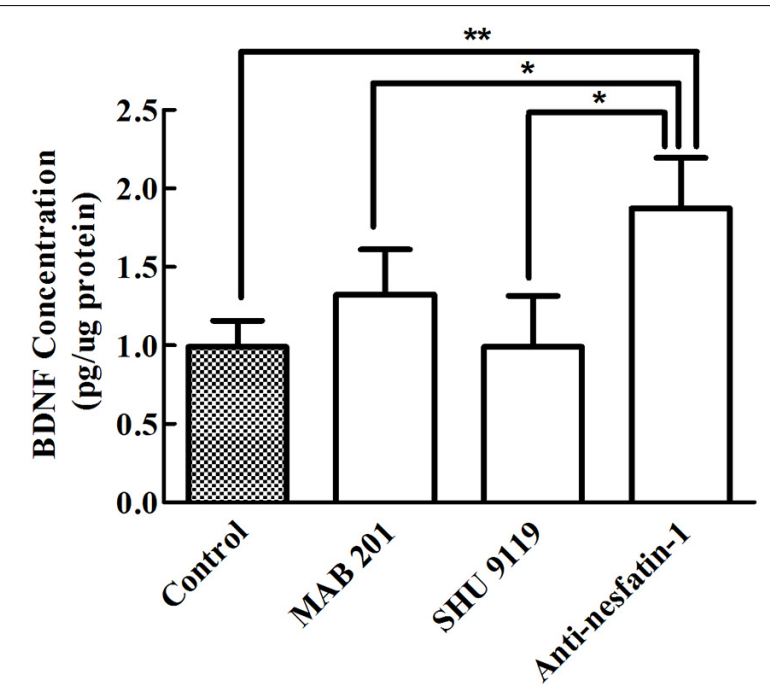

FIGURE 8 | Anti-nesfatin-1 antibody treatment elevated BDNF levels in the SNpc $(n=6)$. Statistical analysis of BDNF protein levels in control mice and mice treated with MAB 201, SHU 9119 or anti-nesfatin-1 antibody. Each value represents the mean $\pm \mathrm{SD}, n=6$; ${ }^{* *} p<0.005$ and ${ }^{*} p<0.05$. BDNF, brain-derived neurotrophic factor; MAB 201, non-immune anti-mouse IgG antibody; SHU 9119, MC4R receptor inhibitor; SNpc, substantia nigra pars compacta.

level of nesfatin-1 in the CSF by administrating anti-nesfatin-1 antibody into the lateral ventricle greatly reduced the numbers of $\mathrm{TH}(+)$-dopaminergic neurons in the SNpc, as shown by our immunofluorescence study. Second, DA and its metabolism in the striatum were significantly reduced after ICV injection of anti-nesfatin-1 antibody, as shown by our HPLC measurements. Furthermore, subcellular structures such as mitochondria and nuclei in dopaminergic neurons were severely damaged in animals treated with anti-nesfatin-1 antibody. Thus, these data support a critical role of nesfatin- 1 in the CNS in protecting nigral dopaminergic neurons from degeneration.

To understand the mechanisms by which nesfatin-1 exerts its neuroprotective effects, our first step was to examine whether the diminished CSF nesfatin-1 level induced apoptosis in nigral dopaminergic neurons, since cell apoptosis has been repeatedly shown in the literature to be associated with nigral dopaminergic neuron degeneration in postmortem brain tissues from PD patients (Mochizuki et al., 1996; Anglade et al., 1997). The results from the present study clearly showed that the reduction in nesfatin-1 in the CSF resulting from ICV injection of antinesfatin-1 antibody increased the expression of caspase- 3 in the SNpc, which suggests that apoptosis was induced in nigral dopaminergic neurons in the SNpc.

Our next step was to evaluate the structural integrity of mitochondria and the nucleus because evidence in the literature has established that damaged mitochondria may lose their ability to produce energy to support normal cell functionality, leading to neuronal apoptosis, which is involved in dopaminergic neuron degeneration (Ryan et al., 2015; Bose and Beal, 2016; Ganguly et al., 2017; Golpich et al., 2017; Larsen et al., 2018; Surmeier, 2018; Grünewald et al., 2019). Data from the PD brain also show that mitochondrial dysfunction can increase the production of reactive oxygen species (ROS) by reducing the supply of adenosine triphosphate and blocking energy production (Iversen and Iversen, 2007; Ryan et al., 2015; Bose and Beal, 2016). The ROS produced in mitochondria can further lead to the opening of mitochondrial permeability transition pores and the hyperpolarization of the mitochondrial membrane (Zorov et al., 2014). In turn, the damaged mitochondrial membrane allows the leakage of cytochrome $\mathrm{C}$ into the cytoplasm, which activates caspase-3 and caspase-3 dependent apoptosis (Przedborski and Vila, 2001; Schapira and Jenner, 2011; Subramaniam and Chesselet, 2013). Our TEM data indicated a substantial decline in mitochondrial numbers in dopaminergic neurons and a significantly shortened length of the long axis of mitochondria after the levels of nesfatin-1 in the CSF were significantly reduced. Moreover, the nuclei in the dopamine neurons were also markedly shrunken. Combining the observations of caspase3 activation, mitochondrial dysfunction, and nuclear shrinkage, we propose that decreased nesfatin-1 in the CNS may cause mitochondrial lesions in dopaminergic neurons, which may subsequently activate the apoptosis cascade and ultimately lead to the degeneration of dopaminergic neurons.

Studies in the literature have shown that ERK is involved in neuronal cell survival (Fei et al., 2015; Jeong et al., 2017; Shi et al., 2017); in particular, the state of ERK1/2 activation may determine whether the kinase promotes cell death or promotes cell survival (Stanciu et al., 2000; Chang and Karin, 2001; Stanciu and DeFranco, 2002; Chu et al., 2004). Yin et al. (2008) demonstrated that chronic manganese exposure in rats results in a significant activation of astrocytic caspase- 3 and $p$-ERK that mediates the apoptosis of astrocytes. Our Western blot data 
revealed a significant activation of $p$-ERK in the $\mathrm{SNpc}$ following injection of anti-nesfatin-1 antibody into the CSF. Thus, it seems likely that diminished nesfatin-1 levels in the CNS may weaken the ability of cells to protect mitochondria in dopamine neurons, which may cause the overexpression of $p$-ERK, leading to the apoptosis of dopamine neurons.

Brain-derived neurotrophic factor, a known neurotrophic factor, exerts neuroprotective effects, including anti-apoptotic, and antioxidative effects as well as suppression of autophagy ( $\mathrm{Wu}$ et al., 2016, 2017; Chen et al., 2017). A significant increase in $\mathrm{BDNF}$ levels in the SNpc following the reduction of nesfatin1 was evident in the current research. Since anti-nesfatin-1 antibody treatment greatly reduced the number of dopaminergic neurons (by 23\%), it is possible that the increased BDNF may reflect a compensatory response that offsets the loss of dopaminergic neurons (Hassani et al., 2019).

Finally, does nesfatin-1 exert its neuroprotective effect by acting on its putative receptor, i.e., MC4R? Our previous study showed that nesfatin-1 postsynaptically inhibits the electrical activity of nigral dopaminergic neurons, suggesting that nesfatin1 receptors are expressed in dopaminergic neurons ( $\mathrm{Li}$ et al., 2014). A number of candidate nesfatin-1 receptors have been proposed, including MC4R, corticotropin-releasing factor type 2 receptor, and natriuretic peptide receptor $\mathrm{A}$ (Yosten and Samson, 2009; Angelone et al., 2013; Ying et al., 2015). Initially, we hypothesized that the effect of nesfatin-1 on dopaminergic neurons may be mediated through its binding to MC4R, while the expression of MC4R in the SNpc was indeed confirmed by our current study. Injection of a specific MC4R inhibitor, SHU 9119, into the lateral ventricle neither caused nigral dopaminergic lesions [i.e., $\mathrm{TH}(+)$-dopaminergic neurons, DA levels] nor induced apoptosis (i.e., caspase-3) or other related signaling pathways (i.e., ERK1/2 and BDNF). Thus, it is highly unlikely that MC4R is involved in the function of nesfatin-1 in protecting dopamine neurons in the SNpc.

In summary, our data demonstrate that reducing the nesfatin1 concentration in the CSF by administering anti-nesfatin1 antibody into the lateral ventricle can induce nigrostriatal

\section{REFERENCES}

Alieva, A. K., Zyrin, V. S., Rudenok, M. M., Kolacheva, A. A., Shulskaya, M. V., Ugryumov, M. V., et al. (2018). Whole-transcriptome analysis of mouse models with MPTP-induced early stages of Parkinson's disease reveals stage-specific response of transcriptome and a possible role of myelin-linked genes in neurodegeneration. Mol. Neurobiol. 55, 7229-7241. doi: 10.1007/s12035-0180907-1

Allen, S. J., Watson, J. J., Shoemark, D. K., Barua, N. U., and Patel, N. K. (2013). GDNF, NGF and BDNF as therapeutic options for neurodegeneration. Pharmacol. Ther. 138, 155-175. doi: 10.1016/j.pharmthera.2013.01.004

Angelone, T., Filice, E., Pasqua, T., Amodio, N., Galluccio, M., Montesanti, G., et al. (2013). Nesfatin-1 as a novel cardiac peptide: identification, functional characterization, and protection against ischemia/reperfusion injury. Cell Mol. Life Sci. 70, 495-509. doi: 10.1007/s00018-012-1138-7

Anglade, P., Vyas, S., Javoy-Agid, F., Herrero, M. T., Michel, P. P., Marquez, J., et al. (1997). Apoptosis and autophagy in nigral neurons of patients with Parkinson's disease. Histol. Histopathol. 12, 25-31.

Atsuchi, K., Asakawa, A., Ushikai, M., Ataka, K., Tsai, M., Koyama, K., et al. (2010). Centrally administered nesfatin-1 inhibits feeding behaviour and dopaminergic system degeneration in vivo. This effect may be mediated by apoptosis triggered by mitochondrial dysfunction. Our study provides new evidence that nesfatin-1 plays a role in maintaining the normal physiological function of the nigrostriatal system. Further investigation with nesfatin-1 knockout mice is needed to demonstrate the effect of nesfatin-1 on the nigrostriatal dopaminergic system.

\section{DATA AVAILABILITY STATEMENT}

The original contributions presented in the study are included in the article/supplementary material, further inquiries can be directed to the corresponding author/s.

\section{ETHICS STATEMENT}

The animal study was reviewed and approved by Animal Ethics Committee of Qingdao University.

\section{AUTHOR CONTRIBUTIONS}

HC, XL, and HM conducted the experiments. XL wrote the manuscript. WZ revised the manuscript. XS conceived the idea and revised the manuscript. All authors have approved the manuscript.

\section{FUNDING}

This study was funded by grants from China National Foundation of Natural Science (81701377). Dr. Zheng's research is partially supported by U.S. National Institutes of Health/NIEHS (R01ES027078).

gastroduodenal motility in mice. Neuroreport 21, 1008-1011. doi: 10.1097/ WNR.0b013e32833f7b96

Balestrino, R., and Schapira, A. H. V. (2020). Parkinson disease. Eur. J. Neurol. 27, 27-42. doi: 10.1111/ene.14108

Beitz, J. M. (2014). Parkinson's disease: a review. Front. Biosci. (Schol Ed) 6:65-74. doi: $10.2741 / \mathrm{s} 415$

Blanchard, V., Raisman-Vozari, R., Savasta, M., Hirsch, E., Javoy-Agid, F., Feuerstein, C., et al. (1993). Cellular quantification of tyrosine hydroxylase in the rat brain by immunoautoradiography. J. Neurochem. 61, 617-626. doi: 10.1111/j.1471-4159.1993.tb02166.x

Bonam, S. R., and Muller, S. (2020). Parkinson's disease is an autoimmune disease: a reappraisal. Autoimmun. Rev. 19:102684. doi: 10.1016/j.autrev.2020. 102684

Bose, A., and Beal, M. F. (2016). Mitochondrial dysfunction in Parkinson's disease. J. Neurochem. 139(Suppl. 1), 216-231. doi: 10.1111/jnc.13731

Boulos, C., Yaghi, N., El Hayeck, R., Heraoui, G. N., and Fakhoury-Sayegh, N. (2019). Nutritional risk factors, microbiota and Parkinson's disease: what is the current evidence? Nutrients 11:1896. doi: 10.3390/nu11081896

Brailoiu, G. C., Deliu, E., Tica, A. A., Rabinowitz, J. E., Tilley, D. G., Benamar, K., et al. (2013). Nesfatin-1 activates cardiac vagal neurons of nucleus ambiguus 
and elicits bradycardia in conscious rats. J. Neurochem. 126, 739-748. doi: $10.1111 /$ jnc. 12355

Brailoiu, G. C., Dun, S. L., Brailoiu, E., Inan, S., Yang, J., Chang, J. K., et al. (2007). Nesfatin-1: distribution and interaction with a $\mathrm{G}$ protein-coupled receptor in the rat brain. Endocrinology 148, 5088-5094. doi: 10.1210/en.2007-0701

Cacabelos, R. (2017). Parkinson's disease: from pathogenesis to pharmacogenomics. Int. J. Mol. Sci. 18:551. doi: 10.3390/ijms18030551

Calsolaro, V., and Edison, P. (2015). Novel GLP-1 (Glucagon-Like Peptide-1) analogues and insulin in the treatment for Alzheimer's disease and other neurodegenerative diseases. CNS Drugs 29, 1023-1039. doi: 10.1007/s40263015-0301-8

Chang, L., and Karin, M. (2001). Mammalian MAP kinase signalling cascades. Nature 410, 37-40. doi: 10.1038/35065000

Chen, S. D., Wu, C. L., Hwang, W. C., and Yang, D. I. (2017). More insight into BDNF against neurodegeneration: anti-apoptosis, anti-oxidation, and suppression of autophagy. Int. J. Mol. Sci. 18:545. doi: 10.3390/ijms18030545

Chu, C. T., Levinthal, D. J., Kulich, S. M., Chalovich, E. M., and DeFranco, D. B. (2004). Oxidative neuronal injury. The dark side of ERK1/2. Eur. J. Biochem. 271, 2060-2066. doi: 10.1111/j.1432-1033.2004.04132.x

Clynen, E., Swijsen, A., Raijmakers, M., Hoogland, G., and Rigo, J. M. (2014). Neuropeptides as targets for the development of anticonvulsant drugs. Mol. Neurobiol. 50, 626-646. doi: 10.1007/s12035-014-8669-x

Daubner, S. C., Le, T., and Wang, S. (2011). Tyrosine hydroxylase and regulation of dopamine synthesis. Arch. Biochem. Biophys. 508, 1-12. doi: 10.1016/j.abb. 2010.12.017

Dauer, W., and Przedborski, S. (2003). Parkinson's disease: mechanisms and models. Neuron 39, 889-909. doi: 10.1016/s0896-6273(03)00568-3

Dawson, T. M., and Dawson, V. L. (2003). Molecular pathways of neurodegeneration in Parkinson's disease. Science 302, 819-822. doi: $10.1126 /$ science. 1087753

de Lau, L. M., and Breteler, M. M. (2006). Epidemiology of Parkinson's disease. Lancet Neurol. 5, 525-535. doi: 10.1016/s1474-4422(06)70471-9

Delamarre, A., and Meissner, W. G. (2017). Epidemiology, environmental risk factors and genetics of Parkinson's disease. Presse Med. 46(2 Pt 1), 175-181. doi: 10.1016/j.lpm.2017.01.001

Dong, D., Xie, J., and Wang, J. (2019). Neuroprotective effects of brain-gut peptides: a potential therapy for Parkinson's disease. Neurosci. Bull. 35, 10851096. doi: 10.1007/s12264-019-00407-3

Dore, R., Levata, L., Gachkar, S., Jöhren, O., Mittag, J., Lehnert, H., et al. (2017). The thermogenic effect of nesfatin-1 requires recruitment of the melanocortin system. J. Endocrinol. 235, 111-122. doi: 10.1530/joe-17-0151

Elbaz, A., Carcaillon, L., Kab, S., and Moisan, F. (2016). Epidemiology of Parkinson's disease. Rev. Neurol. (Paris) 172, 14-26. doi: 10.1016/j.neurol.2015. 09.012

Emir, G. K., Ünal, Y., Yılmaz, N., Tosun, K., and Kutlu, G. (2019). The association of low levels of nesfatin-1 and glucagon-like peptide-1 with oxidative stress in Parkinson's disease. Neurol. Sci. 40, 2529-2535. doi: 10.1007/s10072-01903975-4

Eustaquio, T., Wang, C., Dugard, C. K., George, N. I., Liu, F., Slikker, W. Jr., et al. (2018). Electron microscopy techniques employed to explore mitochondrial defects in the developing rat brain following ketamine treatment. Exp. Cell Res. 373, 164-170. doi: 10.1016/j.yexcr.2018.10.009

Evans, C. E., Thomas, R. S., Freeman, T. J., Hvoslef-Eide, M., Good, M. A., and Kidd, E. J. (2019). Selective reduction of APP-BACE1 activity improves memory via NMDA-NR2B receptor-mediated mechanisms in aged PDAPP mice. Neurobiol. Aging 75, 136-149. doi: 10.1016/j.neurobiolaging.2018.11.011

Fathalla, A. M., Soliman, A. M., and Moustafa, A. A. (2017). Selective A(2A) receptors blockade reduces degeneration of substantia nigra dopamine neurons in a rotenone-induced rat model of Parkinson's disease: a histological study. Neurosci. Lett. 643, 89-96. doi: 10.1016/j.neulet.2017.02.036

Fei, F., Li, J., Rao, W., Liu, W., Chen, X., Su, N., et al. (2015). Upregulation of Homerla promoted retinal ganglion cell survival after retinal ischemia and reperfusion via interacting with Erk pathway. Cell Mol. Neurobiol. 35, 1039-1048. doi: 10.1007/s10571-015-0198-2

Franco-Iborra, S., Vila, M., and Perier, C. (2016). The Parkinson disease mitochondrial hypothesis: where are we at? Neuroscientist 22, 266-277. doi: $10.1177 / 1073858415574600$
Friedrich, T., Schalla, M. A., Scharner, S., Kühne, S. G., Goebel-Stengel, M., Kobelt, P., et al. (2019). Intracerebroventricular injection of phoenixin alters feeding behavior and activates nesfatin-1 immunoreactive neurons in rats. Brain Res. 1715, 188-195. doi: 10.1016/j.brainres.2019.03.034

Ganguly, G., Chakrabarti, S., Chatterjee, U., and Saso, L. (2017). Proteinopathy, oxidative stress and mitochondrial dysfunction: cross talk in Alzheimer's disease and Parkinson's disease. Drug Des. Devel. Ther. 11, 797-810. doi: 10.2147/dddt. s130514

Gilmozzi, V., Gentile, G., Castelo Rueda, M. P., Hicks, A. A., Pramstaller, P. P., Zanon, A., et al. (2020). Interaction of alpha-synuclein with lipids: mitochondrial cardiolipin as a critical player in the pathogenesis of Parkinson's disease. Front. Neurosci. 14:578993. doi: 10.3389/fnins.2020.578993

Goebel, M., Stengel, A., Wang, L., and Taché, Y. (2011). Central nesfatin-1 reduces the nocturnal food intake in mice by reducing meal size and increasing intermeal intervals. Peptides 32, 36-43. doi: 10.1016/j.peptides.2010.09.027

Golpich, M., Amini, E., Mohamed, Z., Azman Ali, R., Mohamed Ibrahim, N., and Ahmadiani, A. (2017). Mitochondrial dysfunction and biogenesis in neurodegenerative diseases: pathogenesis and treatment. CNS Neurosci. Ther. 23, 5-22. doi: 10.1111/cns. 12655

Grieco, P., Cai, M., Han, G., Trivedi, D., Campiglia, P., Novellino, E., et al. (2007). Further structure-activity studies of lactam derivatives of MT-II and SHU9119: their activity and selectivity at human melanocortin receptors 3,4 , and 5. Peptides 28, 1191-1196. doi: 10.1016/j.peptides.2007.02.012

Grünewald, A., Kumar, K. R., and Sue, C. M. (2019). New insights into the complex role of mitochondria in Parkinson's disease. Prog. Neurobiol. 177, 73-93. doi: 10.1016/j.pneurobio.2018.09.003

Gu, H., Robison, G., Hong, L., Barrea, R., Wei, X., Farlow, M. R., et al. (2012). Increased $\beta$-amyloid deposition in Tg-SWDI transgenic mouse brain following in vivo lead exposure. Toxicol. Lett. 213, 211-219. doi: 10.1016/j.toxlet.2012.07. 002

Hassani, O. K., Rymar, V. V., Nguyen, K. Q., Huo, L., Cloutier, J. F., Miller, F. D., et al. (2019). The noradrenergic system is necessary for survival of vulnerable midbrain dopaminergic neurons: implications for development and Parkinson's disease. Neurobiol. Aging 85, 22-37. doi: 10.1016/j.neurobiolaging.2019.09.014

Healy-Stoffel, M., Ahmad, S. O., Stanford, J. A., and Levant, B. (2012). A novel use of combined tyrosine hydroxylase and silver nucleolar staining to determine the effects of a unilateral intrastriatal 6-hydroxydopamine lesion in the substantia nigra: a stereological study. J. Neurosci. Methods 210, 187-194. doi: 10.1016/j. jneumeth.2012.07.013

Hruby, V. J., Lu, D., Sharma, S. D., Castrucci, A. L., Kesterson, R. A., alObeidi, F. A., et al. (1995). Cyclic lactam alpha-melanotropin analogues of Ac-Nle4-cyclo[Asp5, D-Phe7,Lys10] alpha-melanocyte-stimulating hormone(4-10)-NH2 with bulky aromatic amino acids at position 7 show high antagonist potency and selectivity at specific melanocortin receptors. J. Med. Chem. 38, 3454-3461. doi: 10.1021/jm00018a005

Iversen, S. D., and Iversen, L. L. (2007). Dopamine: 50 years in perspective. Trends Neurosci. 30, 188-193. doi: 10.1016/j.tins.2007.03.002

Jeong, Y. M., Cheng, X. W., Lee, S., Lee, K. H., Cho, H., Kang, J. H., et al. (2017). Preconditioning with far-infrared irradiation enhances proliferation, cell survival, and migration of rat bone marrow-derived stem cells via CXCR4ERK pathways. Sci. Rep. 7:13718. doi: 10.1038/s41598-017-14219-w

Jiang, H., Li, L. J., Wang, J., and Xie, J. X. (2008). Ghrelin antagonizes MPTPinduced neurotoxicity to the dopaminergic neurons in mouse substantia nigra. Exp. Neurol. 212, 532-537. doi: 10.1016/j.expneurol.2008.05.006

Jiang, Q., Gu, Z., Zhang, G., and Jing, G. (2000). Diphosphorylation and involvement of extracellular signal-regulated kinases (ERK1/2) in glutamateinduced apoptotic-like death in cultured rat cortical neurons. Brain Res. 857, 71-77. doi: 10.1016/s0006-8993(99)02364-1

Jyothi, H. J., Vidyadhara, D. J., Mahadevan, A., Philip, M., Parmar, S. K., Manohari, S. G., et al. (2015). Aging causes morphological alterations in astrocytes and microglia in human substantia nigra pars compacta. Neurobiol. Aging 36, 3321-3333. doi: 10.1016/j.neurobiolaging.2015.08.024

Kaya, O., Yilmaz, M. E., Bayram, S., Gunduz, O., Kizilay, G., and Ozturk, L. (2019). Effects of cannabinoid modulation on hypothalamic nesfatin-1 and insulin resistance. Chin. J. Physiol. 62, 182-187. doi: 10.4103/cjp.Cjp_50_19

Klockgether, T. (2004). Parkinson's disease: clinical aspects. Cell Tissue Res. 318, 115-120. doi: 10.1007/s00441-004-0975-6 
Kühne, S. G., Schalla, M. A., Friedrich, T., Kobelt, P., Goebel-Stengel, M., Long, M., et al. (2018). Nesfatin-1(30-59) injected intracerebroventricularly increases anxiety, depression-like behavior, and anhedonia in normal weight rats. Nutrients 10:1889. doi: 10.3390/nu10121889

Larsen, S. B., Hanss, Z., and Krüger, R. (2018). The genetic architecture of mitochondrial dysfunction in Parkinson's disease. Cell Tissue Res. 373, 21-37. doi: 10.1007/s00441-017-2768-8

Leckstrom, A., Kim, E. R., Wong, D., and Mizuno, T. M. (2009). Xenin, a gastrointestinal peptide, regulates feeding independent of the melanocortin signaling pathway. Diabetes 58, 87-94. doi: 10.2337/db08-0260

Li, C., Zhang, F., Shi, L., Zhang, H., Tian, Z., Xie, J., et al. (2014). Nesfatin-1 decreases excitability of dopaminergic neurons in the substantia nigra. J. Mol. Neurosci. 52, 419-424. doi: 10.1007/s12031-013-0169-3

Mochizuki, H., Goto, K., Mori, H., and Mizuno, Y. (1996). Histochemical detection of apoptosis in Parkinson's disease. J. Neurol. Sci. 137, 120-123. doi: 10.1016/ 0022-510x(95)00336-z

Moore, R. Y., and Bloom, F. E. (1979). Central catecholamine neuron systems: anatomy and physiology of the norepinephrine and epinephrine systems. Annu. Rev. Neurosci. 2, 113-168. doi: 10.1146/annurev.ne.02.030179.000553

Nam, J. H., Park, E. S., Won, S. Y., Lee, Y. A., Kim, K. I., Jeong, J. Y., et al. (2015). TRPV1 on astrocytes rescues nigral dopamine neurons in Parkinson's disease via CNTF. Brain 138(Pt 12), 3610-3622. doi: 10.1093/brain/awv297

Nunnari, J., and Suomalainen, A. (2012). Mitochondria: in sickness and in health. Cell 148, 1145-1159. doi: 10.1016/j.cell.2012.02.035

Oh, I. S., Shimizu, H., Satoh, T., Okada, S., Adachi, S., Inoue, K., et al. (2006). Identification of nesfatin- 1 as a satiety molecule in the hypothalamus. Nature 443, 709-712. doi: 10.1038/nature05162

Özsavcí, D., Erşahin, M., Şener, A., Özakpinar, ÖB., Toklu, H. Z., Akakín, D., et al. (2011). ). The novel function of nesfatin-1 as an anti-inflammatory and antiapoptotic peptide in subarachnoid hemorrhage-induced oxidative brain damage in rats. Neurosurgery 68, 1699-1708; discussion1708. doi: 10.1227/NEU. 0b013e318210f258

Pałasz, A., Krzystanek, M., Worthington, J., Czajkowska, B., Kostro, K., Wiaderkiewicz, R., et al. (2012). Nesfatin-1, a unique regulatory neuropeptide of the brain. Neuropeptides 46, 105-112. doi: 10.1016/j.npep.2011.12.002

Pan, W., Hsuchou, H., and Kastin, A. J. (2007). Nesfatin-1 crosses the blood-brain barrier without saturation. Peptides 28, 2223-2228. doi: 10.1016/j.peptides. 2007.09.005

Park, E. S., Kim, S. R., and Jin, B. K. (2012). Transient receptor potential vanilloid subtype 1 contributes to mesencephalic dopaminergic neuronal survival by inhibiting microglia-originated oxidative stress. Brain Res. Bull. 89, 92-96. doi: 10.1016/j.brainresbull.2012.07.001

Paxinos, G., and Franklin, K. B. J. (2001). The Mouse Brain in Stereotaxic Coordinates. Cambridge, MA: Academic Press.

Peng, S., Wang, C., Ma, J., Jiang, K., Jiang, Y., Gu, X., et al. (2018). Achyranthes bidentata polypeptide protects dopaminergic neurons from apoptosis in Parkinson's disease models both in vitro and in vivo. Br. J. Pharmacol. 175, 631-643. doi: 10.1111/bph.14110

Perier, C., Bové, J., and Vila, M. (2012). Mitochondria and programmed cell death in Parkinson's disease: apoptosis and beyond. Antioxid. Redox Signal. 16, 883-895. doi: 10.1089/ars.2011.4074

Pickrell, A. M., Huang, C. H., Kennedy, S. R., Ordureau, A., Sideris, D. P., Hoekstra, J. G., et al. (2015). Endogenous parkin preserves dopaminergic substantia nigral neurons following mitochondrial DNA mutagenic stress. Neuron 87, 371-381. doi: 10.1016/j.neuron.2015.06.034

Polacchini, A., Metelli, G., Francavilla, R., Baj, G., Florean, M., Mascaretti, L. G., et al. (2015). A method for reproducible measurements of serum BDNF: comparison of the performance of six commercial assays. Sci. Rep. 5:17989. doi: 10.1038/srep17989

Przedborski, S., and Vila, M. (2001). The last decade in Parkinson's disease research, basic sciences. Adv. Neurol. 86, 177-186.

Raisman-Vozari, R., Hirsch, E., Javoy-Agid, F., Vassort, C., Savasta, M., Feuerstein, C., et al. (1991). Quantitative autoradiography of tyrosine hydroxylase immunoreactivity in the rat brain. J. Neurochem. 57, 1212-1222. doi: 10.1111/j. 1471-4159.1991.tb08282.x

Respondek, G., Stamelou, M., and Höglinger, G. U. (2019). Classification of atypical parkinsonism per pathology versus phenotype. Int. Rev. Neurobiol. 149, 37-47. doi: 10.1016/bs.irn.2019.10.003
Rogers, C., Fernandes-Alnemri, T., Mayes, L., Alnemri, D., Cingolani, G., and Alnemri, E. S. (2017). Cleavage of DFNA5 by caspase-3 during apoptosis mediates progression to secondary necrotic/pyroptotic cell death. Nat. Commun. 8:14128. doi: 10.1038/ncomms 14128

Ryan, B. J., Hoek, S., Fon, E. A., and Wade-Martins, R. (2015). Mitochondrial dysfunction and mitophagy in Parkinson's: from familial to sporadic disease. Trends Biochem. Sci. 40, 200-210. doi: 10.1016/j.tibs.2015.02.003

Sarkar, S., Raymick, J., and Imam, S. (2016). Neuroprotective and therapeutic strategies against Parkinson's disease: recent perspectives. Int. J. Mol. Sci. 17:904. doi: 10.3390/ijms17060904

Schägger, H. (2006). Tricine-SDS-PAGE. Nat. Protoc. 1, 16-22. doi: 10.1038/nprot. 2006.4

Schapira, A. H., and Jenner, P. (2011). Etiology and pathogenesis of Parkinson's disease. Mov. Disord. 26, 1049-1055. doi: 10.1002/mds.23732

Shehadeh, J., Double, K. L., Murphy, K. E., Bobrovskaya, L., Reyes, S., Dunkley, P. R., et al. (2019). Expression of tyrosine hydroxylase isoforms and phosphorylation at serine 40 in the human nigrostriatal system in Parkinson's disease. Neurobiol. Dis. 130, 104524. doi: 10.1016/j.nbd.2019.104524

Shen, X., Xia, L., Liu, L., Jiang, H., Shannahan, J., Du, Y., et al. (2020). Altered clearance of beta-amyloid from the cerebrospinal fluid following subchronic lead exposure in rats: roles of RAGE and LRP1 in the choroid plexus. J. Trace Elem. Med. Biol. 61:126520. doi: 10.1016/j.jtemb.2020.126520

Shen, X. L., Song, N., Du, X. X., Li, Y., Xie, J. X., and Jiang, H. (2017). Nesfatin-1 protects dopaminergic neurons against MPP(+)/MPTP-induced neurotoxicity through the C-Raf-ERK1/2-dependent anti-apoptotic pathway. Sci. Rep. 7:40961. doi: 10.1038/srep40961

Shi, G., Du, Y., Li, Y., An, Y., He, Z., Lin, Y., et al. (2017). Cell recognition molecule L1 regulates cell surface glycosylation to modulate cell survival and migration. Int. J. Med. Sci. 14, 1276-1283. doi: 10.7150/ijms.20479

Stanciu, M., and DeFranco, D. B. (2002). Prolonged nuclear retention of activated extracellular signal-regulated protein kinase promotes cell death generated by oxidative toxicity or proteasome inhibition in a neuronal cell line. J. Biol. Chem. 277, 4010-4017. doi: 10.1074/jbc.M104479200

Stanciu, M., Wang, Y., Kentor, R., Burke, N., Watkins, S., Kress, G., et al. (2000). Persistent activation of ERK contributes to glutamate-induced oxidative toxicity in a neuronal cell line and primary cortical neuron cultures. J. Biol. Chem. 275, 12200-12206. doi: 10.1074/jbc.275.16.12200

Stengel, A., Goebel, M., and Taché, Y. (2011). Nesfatin-1: a novel inhibitory regulator of food intake and body weight. Obes. Rev. 12, 261-271. doi: 10.1111/ j.1467-789X.2010.00770.x

Stengel, A., Goebel, M., Wang, L., and Taché, Y. (2010). Ghrelin, des-acyl ghrelin and nesfatin-1 in gastric X/A-like cells: role as regulators of food intake and body weight. Peptides 31, 357-369. doi: 10.1016/j.peptides.2009.11.019

Stengel, A., and Taché, Y. (2011). Minireview: nesfatin-1-an emerging new player in the brain-gut, endocrine, and metabolic axis. Endocrinology 152, 4033-4038. doi: 10.1210/en.2011-1500

St-Gelais, F., Jomphe, C., and Trudeau, L. E. (2006). The role of neurotensin in central nervous system pathophysiology: what is the evidence? J. Psychiatry Neurosci. 31, 229-245.

Su, Y., Zhang, J., Tang, Y., Bi, F., and Liu, J. N. (2010). The novel function of nesfatin-1: anti-hyperglycemia. Biochem. Biophys. Res. Commun. 391, 10391042. doi: 10.1016/j.bbrc.2009.12.014

Subramaniam, S. R., and Chesselet, M. F. (2013). Mitochondrial dysfunction and oxidative stress in Parkinson's disease. Prog. Neurobiol. 10, 17-32. doi: 10.1016/ j.pneurobio.2013.04.004

Surmeier, D. J. (2018). Determinants of dopaminergic neuron loss in Parkinson's disease. FEBS J. 285, 3657-3668. doi: 10.1111/febs.14607

Tan, Z., Xu, H., Shen, X., and Jiang, H. (2015). Nesfatin-1 antagonized rotenoneinduced neurotoxicity in MES23.5 dopaminergic cells. Peptides 69, 109-114. doi: 10.1016/j.peptides.2015.04.019

Tang, C. H., Fu, X. J., Xu, X. L., Wei, X. J., and Pan, H. S. (2012). The antiinflammatory and anti-apoptotic effects of nesfatin-1 in the traumatic rat brain. Peptides 36, 39-45. doi: 10.1016/j.peptides.2012.04.014

Weibert, E., Hofmann, T., and Stengel, A. (2019). Role of nesfatin-1 in anxiety, depression and the response to stress. Psychoneuroendocrinology 100, 58-66. doi: 10.1016/j.psyneuen.2018.09.037

Wu, C. L., Chen, C. H., Hwang, C. S., Chen, S. D., Hwang, W. C., and Yang, D. I. (2017). Roles of p62 in BDNF-dependent autophagy suppression and 
neuroprotection against mitochondrial dysfunction in rat cortical neurons. J. Neurochem. 140, 845-861. doi: 10.1111/jnc.13937

Wu, C. L., Chen, S. D., Yin, J. H., Hwang, C. S., and Yang, D. I. (2016). Nuclear factor-kappaB-dependent Sestrin2 induction mediates the antioxidant effects of BDNF against mitochondrial inhibition in rat cortical neurons. Mol. Neurobiol. 53, 4126-4142. doi: 10.1007/s12035-015-9357-1

Yang, Y., Chen, M., Lai, Y., Gantz, I., Georgeson, K. E., and Harmon, C. M. (2002). Molecular determinants of human melanocortin-4 receptor responsible for antagonist SHU9119 selective activity. J. Biol. Chem. 277, 20328-20335. doi: 10.1074/jbc.M201343200

Yin, Z., Aschner, J. L., dos Santos, A. P., and Aschner, M. (2008). Mitochondrialdependent manganese neurotoxicity in rat primary astrocyte cultures. Brain Res. 1203, 1-11. doi: 10.1016/j.brainres.2008.01.079

Ying, J., Zhang, Y., Gong, S., Chang, Z., Zhou, X., Li, H., et al. (2015). Nesfatin-1 suppresses cardiac L-type $\mathrm{Ca}^{2+}$ channels through melanocortin Type 4 receptor and the novel protein Kinase $\mathrm{C}$ theta isoform pathway. Cell Physiol. Biochem. 36, 555-568. doi: 10.1159/000430120

Yosten, G. L., and Samson, W. K. (2009). Nesfatin-1 exerts cardiovascular actions in brain: possible interaction with the central melanocortin system. Am. J. Physiol. Regul. Integr. Comp. Physiol. 297, R330-R336. doi: 10.1152/ajpregu. 90867.2008

Young, C. N., Cao, X., Guruju, M. R., Pierce, J. P., Morgan, D. A., Wang, G., et al. (2012). ER stress in the brain subfornical organ mediates angiotensindependent hypertension. J. Clin. Invest. 122, 3960-3964. doi: 10.1172/jci64583

$\mathrm{Yu}$, J., Xu, H., Shen, X., and Jiang, H. (2016). Ghrelin protects MES23.5 cells against rotenone via inhibiting mitochondrial dysfunction and apoptosis. Neuropeptides 56, 69-74. doi: 10.1016/j.npep.2015.09.011
Zhang, H. Y., Song, N., Jiang, H., Bi, M. X., and Xie, J. X. (2014). Brain-derived neurotrophic factor and glial cell line-derived neurotrophic factor inhibit ferrous iron influx via divalent metal transporter 1 and iron regulatory protein 1 regulation in ventral mesencephalic neurons. Biochim. Biophys. Acta 1843, 2967-2975. doi: 10.1016/j.bbamcr.2014.09.010

Zhang, N., Li, J., Wang, H., Xiao, L., Wei, Y., He, J., et al. (2018). The level of Nesfatin-1 in a mouse gastric cancer model and its role in gastric cancer comorbid with depression. Shanghai Arch. Psychiatry 30, 119-126. doi: 10. 11919/j.issn.1002-0829.217152

Zhang, P., Chen, L., Zhao, Q., Du, X., Bi, M., Li, Y., et al. (2020). Ferroptosis was more initial in cell death caused by iron overload and its underlying mechanism in Parkinson's disease. Free Radic. Biol. Med 152, 227-234. doi: 10.1016/j.freeradbiomed.2020.03.015

Zorov, D. B., Juhaszova, M., and Sollott, S. J. (2014). Mitochondrial reactive oxygen species (ROS) and ROS-induced ROS release. Physiol. Rev. 94, 909-950. doi: 10.1152/physrev.00026.2013

Conflict of Interest: The authors declare that the research was conducted in the absence of any commercial or financial relationships that could be construed as a potential conflict of interest.

Copyright (c) 2021 Chen, Li, Ma, Zheng and Shen. This is an open-access article distributed under the terms of the Creative Commons Attribution License (CC BY). The use, distribution or reproduction in other forums is permitted, provided the original author(s) and the copyright owner(s) are credited and that the original publication in this journal is cited, in accordance with accepted academic practice. No use, distribution or reproduction is permitted which does not comply with these terms. 